\title{
Antiarrhythmic properties of novel \\ antianginal drugs in dog and human \\ cardiac preparations
}

PhD Thesis

Dr. Tamás Szél

Department of Pharmacology and Pharmacotherapy

University of Szeged

Szeged

Hungary

2012 


\section{STUDIES RELATED TO THE THESIS}

I. Szél Tamás, Koncz István, Jost Norbert, Baczkó István, Husti Zoltán, Virág László, Bussek Alexandra, Wettwer Erich, Ravens Ursula, Papp Gyula, Varró András

Class I/B antiarrhythmic property of ranolazine, a novel antianginal agent, in dog and human cardiac preparations

European Journal of Pharmacology, 2011, 662(1-3):31-39.

IF.: 2,516

II. Koncz István, Szél Tamás, Bitay Miklós, Cerbai Elisabetta, Jaeger Kristian, Fülöp Ferenc, Jost Norbert, Virág László, Orvos Péter, Tálosi László, Kristóf Attila, Baczkó István, Papp J Gyula, Varró András

Electrophysiological effects of ivabradine in dog and human cardiac preparations: Potential antiarrhythmic actions

European Journal of Pharmacology, 2011, 668(3):419-426.

IF.: 2,516

III. Koncz Istán, Szél Tamás, Jaeger Kristian, Baczkó István, Cerbai Elisabetta, Romanelli M Novella, Papp J Gyula, Varró András

Selective pharmacological inhibition of the pacemaker channel isoforms (HCN1-4) as new possible therapeutical targets

Current Medicinal Chemistry, 2011, 18(24):3662-74.

IF.: 4,859

\section{OTHER STUDIES}

I. Esther Pueyo, Alberto Corrias, László Virág, Norbert Jost, Tamás Szél, András Varró, Norbert Szentandrássy|, Péter P. Nánási, Kevin Burrage, Blanca Rodríguez

A multi-scale investigation of repolarization variability and its role in cardiac arrhythmogenesis

Biophysical Journal, 2011, 101(12):2892-902.

IF.: 3,653

II. Martina Del Lungo, Michele Melchiorre, Luca Guandalini, Laura Sartiani, Alessandro Mugelli, István Koncz, Tamás Szél, András Varró, Maria Novella Romanelli, Elisabetta Cerbai

Novel blockers of hyperpolarization-activated current with isoform selectivity in recombinant cells and native tissue

British Journal of Pharmacology, 2011, 166(2):602-16.

IF.: 4,409 


\section{ACRONYMS AND ABREVIATIONS}

AERP: atrial effective refractory period

AF: atrial fibrillation

AP: action potential

APA: action potential amplitude

APD: action potential duration

$\mathbf{A P D}_{\mathbf{5 0}}$ and $\mathbf{A P D}_{\mathbf{9 0}}$ : action potential durations at $50 \%$ and $90 \%$ of repolarization

ATP: adenosine-triphosphate

cAMP: cyclic adenosine-monophosphate

CT: conduction time

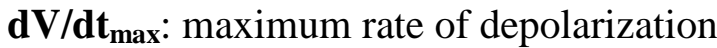

ERP: effective refractory period

HCN: hyperpolarization-activated and cyclic nucleotide-gated channel

$\mathbf{I}_{\mathrm{Ca}}: \mathrm{Ca}^{2+}$ current

If: 'funny' current, cardiac pacemaker current

$\mathbf{I}_{\mathbf{K} 1}$ : inward rectifier $\mathrm{K}^{+}$current

$\mathbf{I}_{\mathbf{K}(\mathbf{A T P})}$ : ATP-sensitive potassium current

$\mathbf{I}_{\mathbf{K r}}$ : rapid component of the delayed rectifier $\mathrm{K}^{+}$current

$\mathbf{I}_{\mathbf{K s}}$ : slow component of the delayed rectifier $\mathrm{K}^{+}$current

$\mathbf{I}_{\mathrm{Na}}: \mathrm{Na}^{+}$current

$\mathbf{I}_{\mathrm{NaK}}: \mathrm{Na}^{+} / \mathrm{K}^{+}$pump current

$\mathbf{I}_{\mathbf{t}_{\mathbf{0}}}$ : transient outward $\mathrm{K}^{+}$current

Late $\mathbf{I}_{\mathrm{Na}}$ : late phase of the inward $\mathrm{Na}^{+}$current

Late $\mathbf{I}_{\mathbf{C a}}$ : late phase of the inward $\mathrm{Ca}^{2+}$ current

MDP: maximum diastolic potential

NCX: $\mathrm{Na}^{+}-\mathrm{Ca}^{2+}$ exchanger

SVT: supraventricular tachycardia

$\mathbf{V}_{\text {max }}$ : maximum rate of depolarization

VT: ventricular tachycardia 


\section{TABLE OF CONTENTS}

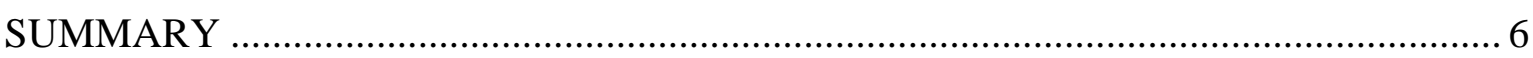

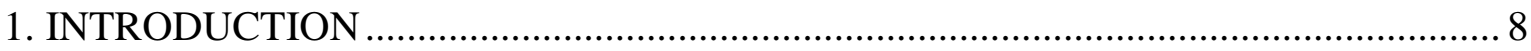

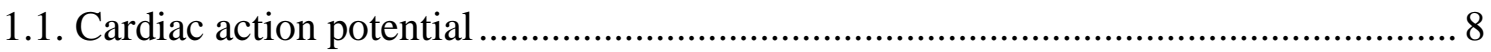

1.2. Antiarrhythmic drugs .................................................................................. 9

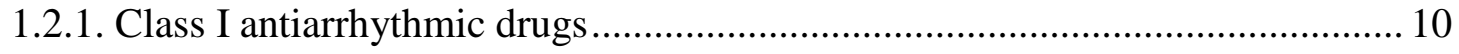

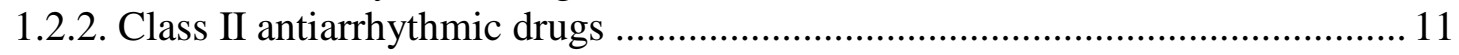

1.2.3. Class III antiarrhythmic drugs .................................................................. 12

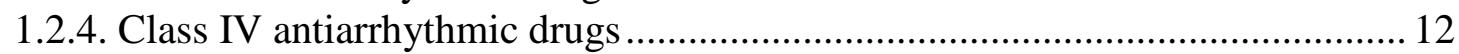

1.2.5. Class V antiarrhythmic drugs ...................................................................... 12

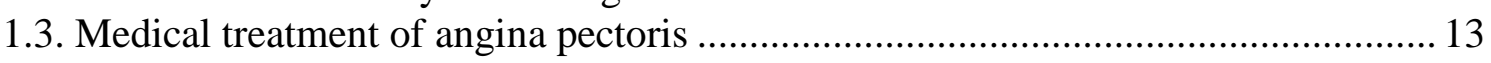

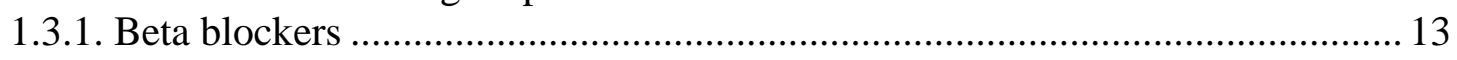

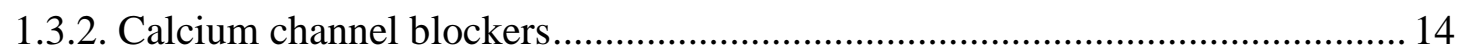

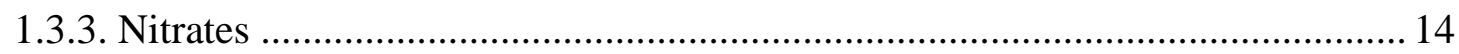

1.3.4. Trimetazidine

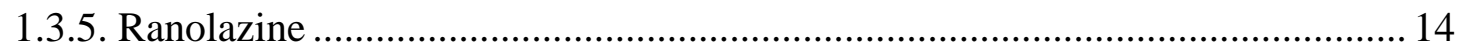

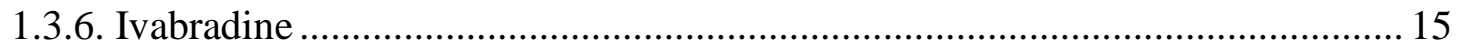

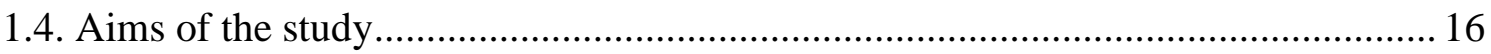

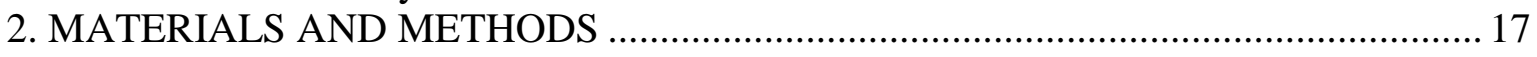

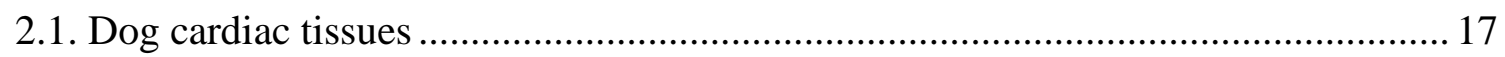

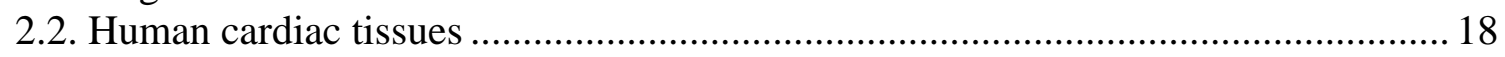

2.3. Conventional microelectrode technique ………………………………………. 18

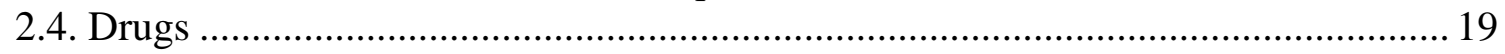

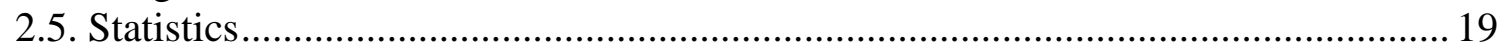

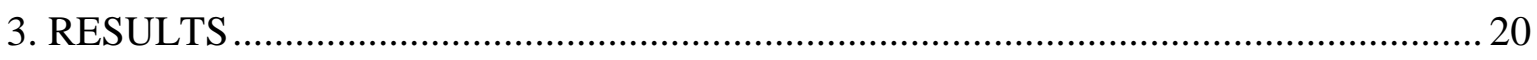

3.1. Effects of ranolazine on transmembrane action potentials ...................................... 20

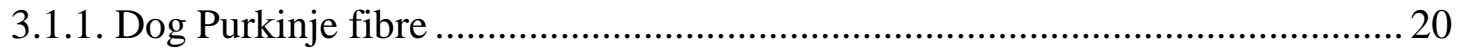

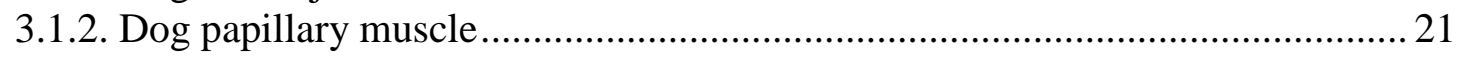

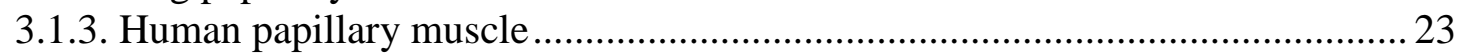

3.1.4. Onset and offset kinetics of $\mathrm{V}_{\max }$ block .......................................................... 24

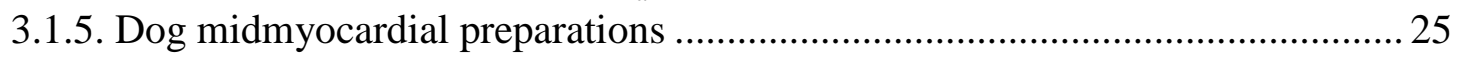

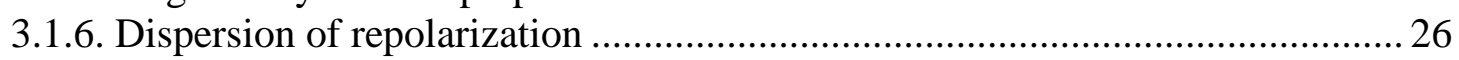

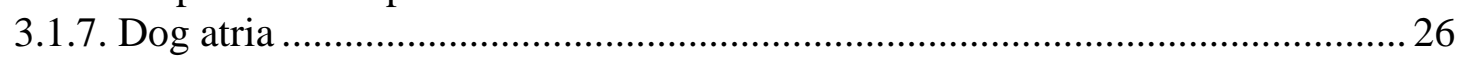

3.2. Effects of ivabradine on transmembrane action potentials...................................... 28

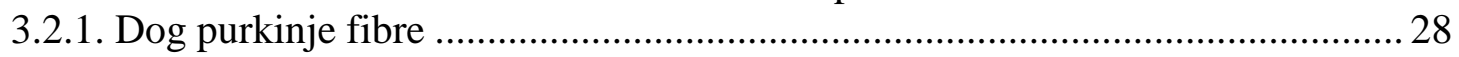

3.2.2. Dog papillary muscle.................................................................................. 30

3.2.3. Human papillary muscle ................................................................................. 31

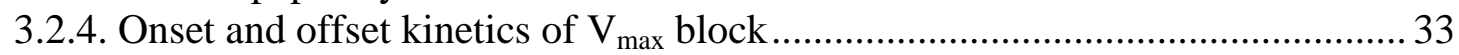

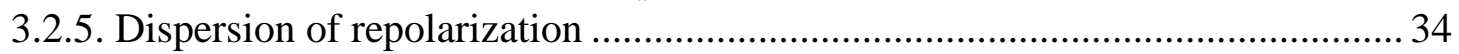

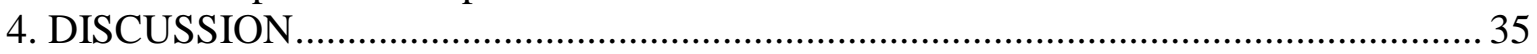

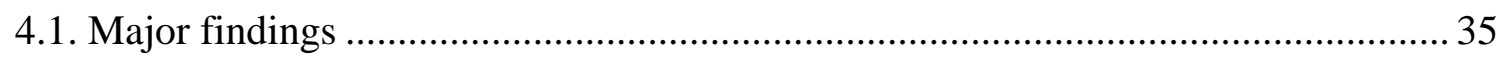

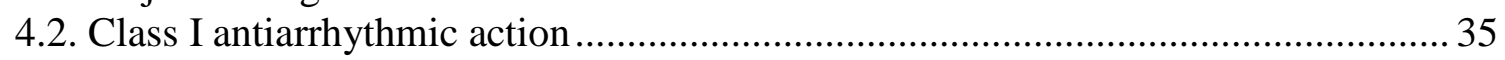

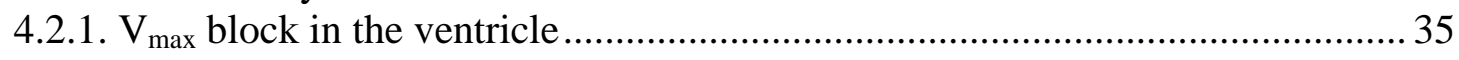

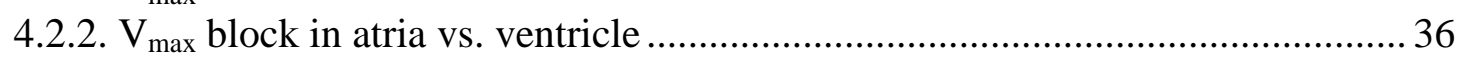

4.2.3. $\mathrm{V}_{\max }$ block in normal vs. remodelled atria.......................................................... 37

4.2.4. $\mathrm{V}_{\max }$ block in case of elevated extracellular potassium concentration ................ 37

4.3. Class III antiarrhythmic action ............................................................................... 38

4.3.1. Attenuated repolarization reserve .............................................................. 38 


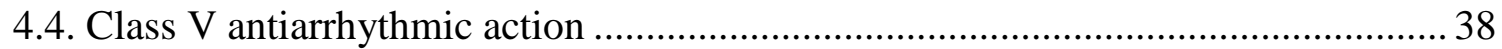

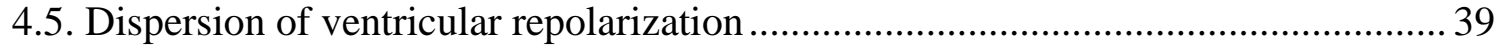

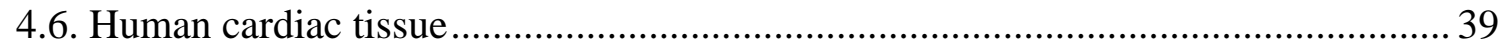

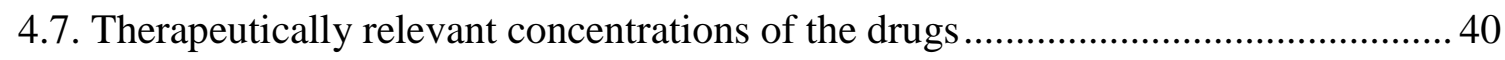

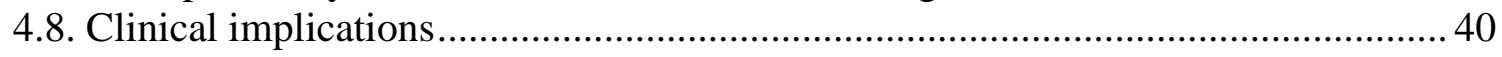

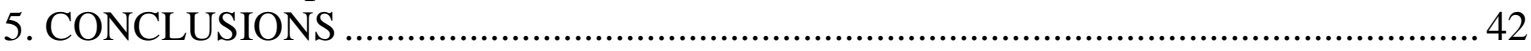

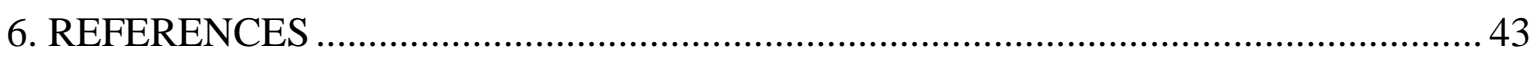

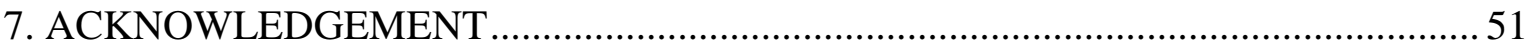




\section{SUMMARY}

Chronic stable angina is an insidious manifestation of coronary artery disease. Pharmacological treatment is the cornerstone of stable angina and is an essential component of the treatment strategy, which also involves beta-blockers, nitrates (or related derivatives) and calcium channel blockers. New classes of treatments (ivabradine, ranolazine) with entirely different mechanisms of action have now been added. Ranolazine reduces ischemia via inhibition of the late phase of the inward sodium current (late $\mathrm{I}_{\mathrm{Na}}$ ) during cardiac repolarization, with a consequent reduction in intracellular sodium and calcium overload. Ivabradine is a novel, heart rate-lowering drug which inhibits the pacemaker $\left(\mathrm{I}_{\mathrm{f}}\right)$ current in the heart with high selectivity and with minimal effect on haemodynamic parameters.

The primary aim of our studies, summarized in this thesis was to investigate in detail the cellular electrophysiological effects of ranolazine and ivabradin in dog and human heart preparations. Using conventional microelectrode technique action potential characteristics were studied.

Our results demonstrate that ranolazine and ivabradine at relatively high concentrations in dog and human cardiac preparations produce a concentration- and frequency-dependent depression of $\mathrm{V}_{\max }$ and able to prolong action potential duration i.e. exerts Class I and III antiarrhythmic actions. Ranolazine produces depression of $\mathrm{V}_{\max }$ with rather fast onset and offset kinetics, i.e. exerts Class I/B antiarrhythmic action (similar to that of mexiletine) not only in normal and remodelled atria, but also in the ventricle. Other important finding is that due to its multiple ion channel blocking property, ranolazine alters the repolarization in a complex manner in remodelled atria. Ivabradine (at high concentrations) can be considered as a $\mathrm{Na}^{+}$channel blocker antiarrhythmic drug with slow kinetic onset and recovery i.e. exerts Class I/C antiarrhythmic action (similar to that of flecainide or propafenone). Depression of $\mathrm{V}_{\max }$ and conduction were more pronounced in case of elevated potassium concentration, e.g. when the resting membrane potential is partly depolarized, even as in the presence of an ischaemic cardiac substrate. Our results support the action potential lengthening effect of ivabardine also in dog and human cardiac preparations especially in case of attenuated repolarization reserve. Ranolazine decreases (and ivabradine does not increase) the dispersion of repolarization between Purkinje fibres 
and the subendocardial muscle layers), which can contribute to the antiarrhythmic property of the drugs.

We provide evidence that these antianginal drugs are not devoid of subsidiary antiarrhythmic properties, which can be advantageous in the treatment of patients with ischemic heart disease liable to disturbances of cardiac rhythm. 


\section{INTRODUCTION}

\subsection{Cardiac action potential}

The electrophysiologic behavior of the heart is determined by ordered propagation of excitatory stimuli that result in rapid depolarization and slow repolarization, thereby generating action potentials (AP) in myocytes, which reflect the sequental activation and inactivation of inward $\left(\mathrm{Na}^{+}\right.$and $\left.\mathrm{Ca}^{2+}\right)$ and outward $\left(\mathrm{K}^{+}\right)$currents carrying ion channels. The electrical cycle of the myocytes has been divided in five phases (Fig. 1). When the excitation threshold is exceeded, cardiomyocytes are depolarized (phase 0) by a rapid inflow of $\mathrm{Na}^{+}$ions generating a large and fast inward $\mathrm{Na}^{+}$current $\left(\mathrm{I}_{\mathrm{Na}}\right)$. This current determines also the velocity of impulse propagation through the His-Purkinje system, working atrial and ventricular myocytes ('fast-channel tissues'). In sino-atrial and atrioventricular node mainly the $\mathrm{Ca}^{2+}$ current $\left(\mathrm{I}_{\mathrm{Ca}}\right)$ is responsible for depolarization ('slowchannel tissues'). Phase 1 is the initial part of repolarization, mainly governed by the transient outward current $\left(\mathrm{I}_{\mathrm{to}}\right)$. In phase 2, also named plateau, the late components of inward currents (late $\mathrm{I}_{\mathrm{Na}}$, late $\mathrm{I}_{\mathrm{Ca}}$ ) oppose the outward repolarizing currents i.e. the rapid and slow components $\left(\mathrm{I}_{\mathrm{Kr}}\right.$ and $\mathrm{I}_{\mathrm{Ks}}$ ) of the delayed rectifier $\mathrm{K}^{+}$current and the inward rectifier $\mathrm{K}^{+}$current $\left(\mathrm{I}_{\mathrm{K} 1}\right)$. Phase 3 is the terminal part of repolarization, which differs from phase 2 for its faster repolarization rate, the outward gradually overcome the inward currents, enabling fast repolarization of the action potential. The loss of one repolarizing current may not lead to excessive AP lengthening, since other unimpaired $\mathrm{K}^{+}$channels may provide sufficient repolarizing capacity [1-5], i.e. there is a redundancy of the repolarization process ('repolarization reserve'). The key players of the reserve are $\mathrm{I}_{\mathrm{Kr}}, \mathrm{I}_{\mathrm{Ks}}$, $\mathrm{I}_{\mathrm{K} 1}$, and presumably $\mathrm{I}_{\mathrm{to}}$ [2-5]. Phase 4 describes membrane potential during diastole. Timeindependent (or background) currents may also contribute to the whole action potential course i.e. the $\mathrm{Na}^{+} / \mathrm{K}^{+}$pump current $\left(\mathrm{I}_{\mathrm{NaK}}\right)$, the $\mathrm{Na}^{+} / \mathrm{Ca}^{2+}$ exchanger current $\left(\mathrm{I}_{\mathrm{NCX}}\right)$ and the ATP-sensitive poatssium current ( $\left.\mathrm{I}_{\mathrm{K}(\mathrm{ATP})}\right)$. In the sino-atrial node heart rate is regulated by spontaneous electrical pacemaker activity mainly controlled by the $I_{f}$ current [6]. This current determines the slope of diastolic depolarization and cardiac frequency, and its inhibition causes heart rate reduction. The 'funny' $\left(\mathrm{I}_{\mathrm{f}}\right)$ current is so termed because of its unusual characteristics, including that of being an inward current that is activated on hyperpolarization and not on depolarization like other known currents. 


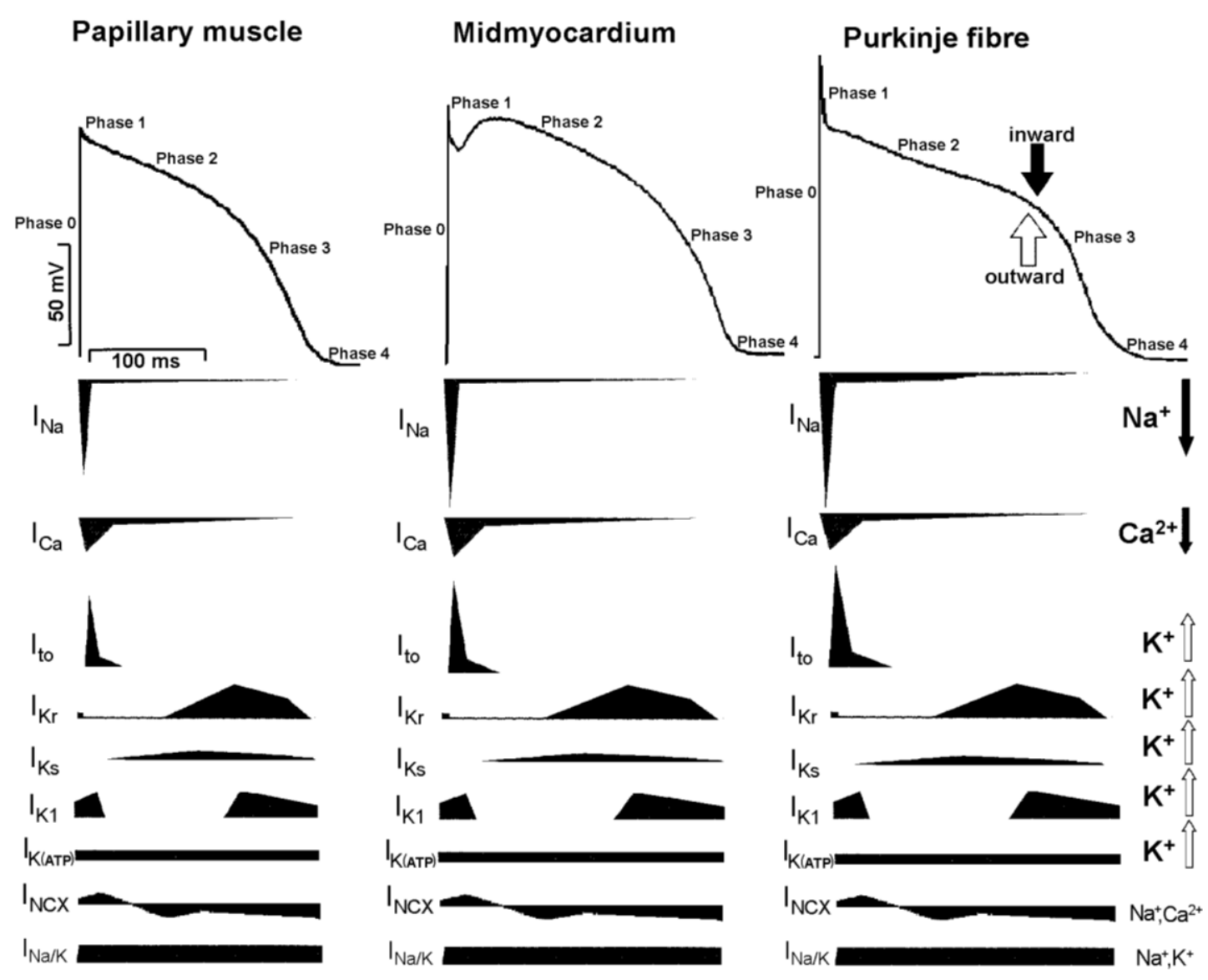

Fig. 1: Action potentials (AP) from papillary musle (endocardium), midmyocardium, Purkinje fibre and corresponding ion currents. The upper panels show representative action potentials and phases of the AP kinetics. Voltage and time calibrations for the action potential recordings are indicated on the left side of the upper panel. The underlying ionic currents are shown in the lower panel in time-match with the AP. The inward currents are depicted as downward deflections. Note that the amplitudes of the currents are not proportional with each other. The ions responsible for the currents are marked at right side of the lower panel

\subsection{Antiarrhythmic drugs}

Most antiarrhythmic agents are traditionally grouped according to Vaughan Williams classification (Table 1) based on their dominant electrophysiological action [7-9]. Class I antiarrhythmic agents have a blockade of the fast-inward sodium channel on myocardium. Class II agents are antisympathetic drugs, particularly the $\beta$-adrenoceptor blockers. Class III drugs act through delaying repolarization of cardiac myocytes and thus cause a lengthening of action potential duration (potassium-channel blockers). Class IV antiarrhythmic drugs are the calcium channel blockers and class $\mathrm{V}$ drugs are specific bradycardic agents. 
Table 1: Classification of antiarrhythmic agents (according to Vaughan Williams)

\begin{tabular}{|c|c|c|c|c|}
\hline & Cellular effects & Ion channel effects & ECG effects & Agents \\
\hline \multicolumn{5}{|l|}{$\begin{array}{l}\text { Class I } \\
\text { Sodium channel } \\
\text { blockers }\end{array}$} \\
\hline //A & $\begin{array}{l}\text {-depress phase } 0 \text { of } \\
\text { action potential even at } \\
\text { normal heart rate } \\
\text {-moderately prolong } \\
\text { repolarization }\end{array}$ & $\begin{array}{l}-\mathrm{Na}^{+} \text {-channel blockade, } \\
\text { intermediate binding and } \\
\text { dissociation properties } \\
-\mathrm{K}^{+} \text {-channel blockade }\end{array}$ & $\begin{array}{l}\text {-QRS widening } \\
\text {-QT interval } \\
\text { prolongation }\end{array}$ & $\begin{array}{l}\text { Quinidine } \\
\text { Procainamide } \\
\text { Disopyramide } \\
\text { Prajmalin } \\
\text { Cibenzolin } \\
\end{array}$ \\
\hline I/B & $\begin{array}{l}\text {-depress phase } 0 \text { only at } \\
\text { high heart rate and } \\
\text { ischemic, depolarized } \\
\text { tissue } \\
\text {-moderately abbreviate } \\
\text { repolarization }\end{array}$ & $\begin{array}{l}\text { - } \mathrm{Na}^{+} \text {-channel blockade, } \\
\text { rapid binding and } \\
\text { dissociation properties }\end{array}$ & $\begin{array}{l}\text {-no change on QRS and } \\
\text { QT interval at normal } \\
\text { heart rate }\end{array}$ & $\begin{array}{l}\text { Lidocain } \\
\text { Mexiletine } \\
\text { Phenytoin } \\
\text { Tocainide }\end{array}$ \\
\hline $\mathrm{I} / \mathrm{C}$ & $\begin{array}{l}\text {-depress phase } 0 \\
\text { markedly even at } \\
\text { normal heart rate }\end{array}$ & $\begin{array}{l}-\mathrm{Na}^{+} \text {-channel blockade, } \\
\text { slow binding and } \\
\text { dissociation properties }\end{array}$ & $\begin{array}{l}\text {-QRS widening } \\
\text {-QT interval } \\
\text { prolongation due to } \\
\text { QRS widening }\end{array}$ & $\begin{array}{l}\text { Flecainide } \\
\text { Propafenone } \\
\text { Encainide } \\
\text { Lorcainide } \\
\text { Morcizine }\end{array}$ \\
\hline $\begin{array}{l}\text { Class II } \\
\text { Beta blocking drugs }\end{array}$ & & $\begin{array}{l}\text {-depress cAMP- } \\
\text { dependent channels }\end{array}$ & -increase on RR interval & $\begin{array}{l}\text { Propranolol } \\
\text { Metoprolol } \\
\text { Pindolol } \\
\text { Esmolol }\end{array}$ \\
\hline $\begin{array}{l}\text { Class III } \\
\text { Potassium channel } \\
\text { blockers }\end{array}$ & $\begin{array}{l}\text {-prolong action potential } \\
\text { duration }\end{array}$ & $-\mathrm{K}^{+}$-channel blockade & $\begin{array}{l}\text {-QT interval } \\
\text { prolongation }\end{array}$ & $\begin{array}{l}\text { Bretylium } \\
\text { Sotalol } \\
\text { Amiodarone } \\
\text { Dofetilide } \\
\text { Almokalant } \\
\text { Ibutilide }\end{array}$ \\
\hline $\begin{array}{l}\text { Class IV } \\
\text { Calcium channel } \\
\text { blockers }\end{array}$ & $\begin{array}{l}\text {-depress depolarization } \\
\text { in nodal tissue }\end{array}$ & $-\mathrm{Ca}^{2+}$-channel blockade & & $\begin{array}{l}\text { Verapamil } \\
\text { Diltiazem }\end{array}$ \\
\hline $\begin{array}{l}\text { Class V } \\
\text { Specific bradycardic } \\
\text { agents }\end{array}$ & $\begin{array}{l}\text {-depress the slope of } \\
\text { diastolic depolarization }\end{array}$ & $\begin{array}{l}-\mathrm{I}_{\mathrm{f}}(\text { pacemaker)-channel } \\
\text { blockade }\end{array}$ & -increase on RR interval & $\begin{array}{l}\text { Anilidine } \\
\text { Zatebradine } \\
\text { Ivabradine }\end{array}$ \\
\hline
\end{tabular}

\subsubsection{Class I antiarrhythmic drugs}

These compounds share the ability to block the fast $\mathrm{Na}^{+}$channels responsible for the upstroke and rapid conduction of the cardiac action potential. In the ECG, this effect may be reflected as widening of the $\mathrm{P}$ wave, widening of the QRS complex, prolongation of the PR interval, or a combination. They are capable not only of slowing but blocking intracardiac conduction and induce arrhythmias. This phenomenon has become widely recognized, and has led to reduction in the usage of these agents. Class I antiarrhythmic drugs usually exert post-repolarization refractoriness, when the refractory period extends well beyond phase 3, even after complete repolarization. Class I drugs are subdivided based on the kinetics of the $\mathrm{Na}^{+}$channel effects, that determine the heart rates at which their electrophysiologic effects become manifest.

i. Class I/A drugs have intermediate kinetics, their fast-channel tissue conduction slowing effects may or may not be evident on an ECG obtained during normal rhythm at 
normal rates. Class $\mathrm{I} / \mathrm{A}$ drugs block repolarizing $\mathrm{K}^{+}$channels also, prolonging the repolarization and refractory periods (the interval from the beginning of the AP until the fiber is able to conduct another AP) of fast-channel tissues. On the ECG, this effect is reflected as QT-interval prolongation even at normal rates.

ii. Class I/B drugs have fast kinetics, they express their electrophysiologic effects only at fast heart rates. Thus, an ECG obtained during normal rhythm at normal rates usually shows no evidence of fast-channel tissue conduction slowing.

iii. Class I/C drugs have slow kinetics, they express their electrophysiologic effects at all heart rates. Thus, an ECG obtained during normal rhythm at normal heart rates usually shows fast-channel tissue conduction slowing. Class I/B drugs and class I/C drugs do not block $\mathrm{K}^{+}$channels directly.

Class I drugs can be useful in supraventricular and ventricular tachyarrhythmias also, but they are not generally recommended for patients with structural heart disorder.

The Cardiac Arrhythmia Suppression Trial (CAST) showed that flecainide and encainide, two Class I/C sodium channel blocker antiarrhythmic drugs, increased mortality rates compared with placebo due to proarrhythmic effects [10]. Consequently, the interest of drug development for treatment of ventricular tachycardia (VT) and atrial fibrillation (AF) has been shifted toward those agents that prevent and terminate re-entrant arrhythmias by prolonging the action potential duration.

\subsubsection{Class II antiarrhythmic drugs}

Class II drugs are $\beta$-blockers. These agents have been given many names in the literature (beta-adrenoceptor blockers, b-adrenergic-blocking agents, b-adrenergic antagonists, b-antagonists, b-adrenergic receptor antagonists). They are particularly used not only for the management of cardiac arrhythmias, but hypertension, angina pectoris, congestive heart failure, essential tremor, glaucoma, migraine prophylaxis and myocardial infarction. As antiarrhythmic agents they suppress beta-adrenergic signaling in the heart by competitively inhibiting agonist binding to beta-adrenergic receptors. They differ from most other antiarrhythmic agents by not directly modifying ion channel function; rather, they prevent the arrhythmia-promoting actions of beta-adrenergic stimulation. They are useful in preventing sudden death due to ventricular tachyarrhythmias associated with acute myocardial ischemia, congenital long QT syndrome, and congestive heart failure. They are also quite valuable in controlling the ventricular rate in patients with atrial fibrillation. $\beta$-blockers affect predominantly slow-channel tissues (SA and AV nodes), 
where they decrease rate of automaticity and slow conduction velocity. Thus, heart rate is slowed and the PR interval is lengthened on the ECG.

Class II drugs are used primarily to treat supraventricular tachycardias (SVT), including sinus tachycardia, AV nodal reentry, atrial fibrillation, and atrial flutter. These drugs are also used to treat VTs to raise the threshold for ventricular fibrillation (VF) and reduce the ventricular proarrhythmic effects of $\beta$-adrenoceptor stimulation.

\subsubsection{Class III antiarrhythmic drugs}

Class III antiarrhythmic action, i.e. lengthening of cardiac action potential duration (APD), is usually caused by blockade of one or more potassium channels [7]. A great number of non-cardiac drugs cause lengthening of APD in both ventricular muscle cells and Purkinje fibres by using a similar mode of action [11-15]. The drugs act also in slowand fast-channel tissues. Because repolarization and refractoriness are prolonged, rate of automaticity is reduced. QT-interval prolongation is the predominant effect on the ECG. These drugs are used to treat supraventricular and ventricular arrhythmias. Class III drugs have a risk of proarrhythmia, particularly torsades de pointes ventricular tachycardia [1619].

\subsubsection{Class IV antiarrhythmic drugs}

Class IV drugs are the nondihydropyridine $\mathrm{Ca}$ channel blockers, which depress $\mathrm{Ca}$ dependent action potentials in slow-channel tissues and thus decrease the rate of automaticity, slow conduction velocity, and prolong refractoriness. Heart rate is slowed, the PR interval is lengthened, and the AV node transmits rapid atrial depolarizations at a lower frequency. These drugs are used primarily to treat supraventricular tachycardias or tachyarrhythmias.

\subsubsection{Class $V$ antiarrhythmic drugs}

Class V drugs are specific bradycardic agents with sino-atrial pacemaker current $\left(\mathrm{I}_{\mathrm{f}}\right)$ inhibitory property. $\mathrm{I}_{\mathrm{f}}$ plays an important role in spontaneous diastolic depolarization [6]. The current flows through hyperpolarization-activated cyclic nucleotide-gated (HCN) channels. Block of the pacemaker currrent reduces the steepness of diastolic depolarization. Thus, heart rate is slowed and the RR interval is lengthened on the ECG. 


\subsection{Medical treatment of angina pectoris}

Stable angina is a form of coronary artery disease. A multifaceted approach is required in the management of angina. It includes lifestyle intervention, medical arsenal and revascularization therapy. The current pharmacological treatment of stable angina pectoris is based on beta adrenoceptor blockers, calcium channel antagonists, nitrates (and related derivatives) and trimetazidine with beneficial metabolic effect on the heart. Number of patients have contraindications or remain unrelieved from anginal discomfort and have relative intolerances to maximum doses of traditional antianginal agents. B-blockers and many calcium channel blockers have similar depressive hemodynamic and significant electrophysiological effects. Therefore antianginal drugs without serious limitations are needed. New classes of treatments (trimetazidine, ivabradine, ranolazine) with entirely different mechanisms of action have now been added.

\subsubsection{Beta blockers}

Heart rate has a prominent role in the development and pathophysiology of myocardial ischaemia. In patients with coronary artery disease, ischaemic episodes could be generated by an elevation in heart rate that elicits imbalance between myocardial oxygen supply and demand. The antiischemic effect of beta blockers is attributable, at least in part, to heart rate reduction and that is regarded as an important therapeutic target in preventing ischaemia by reducing myocardial oxygen consumption. Beta blockers apart from the numerous, proven, valuable effects in the treatment of cardiovascular diseases (angina pectoris, arrhythmias, myocardial infarction, heart failure) have several side effects including bronchospasm, atrioventricular block, lassitude, sleep disturbance, depression, change in lipid status, sexual dysfunction, possible increase in blood sugar level, rebound phenomena. The hemodynamic effects might be also limiting factors at application e.g. the negative inotropic effect. Furthermore beta blockers (except carvedilol and nebivolol) may be contraindicated in patients with peripheral vascular disease. In ST-segment elevation myocardial infarction (STEMI) early i.v. use of beta blockers is clearly contraindicated in patients with clinical signs of hypotension or congestive heart failure [20]. Moreover the advantages of heart rate-lowering by beta-blockers are in part counterbalanced by unmasked alpha-adrenergic coronary vasoconstriction, therefore selective heart ratereducing compounds might be able to decrease heart rate without unmasking alphaadrenergic coronary vasoconstriction [21]. In the absence of contraindications, beta- 
blockers remain the reference treatment to prevent angina attacks, particularly after myocardial infarction.

\subsubsection{Calcium channel blockers}

Calcium channel blockers reduce calcium influx into the cell, producing dual vasodilating and negative inotropic effects, which respectively vary depending on the different compounds. Dihydropyridines (amlodipine, felodipine, isradipine, nicardipine and nifedipine) mostly have a peripheral vasodilating action and could increase heart rate. Usually they must be associated with a beta-blocker or, failing this, with an alternative cardiac slowing agent (e.g. ivabradine). The non-dihydropyridines (diltiazem and verapamil) both have a peripheral vasodilating action and probradycardic and myocardial depressant effects. The hemodynamic effects might be also limiting factors at application (the considerable blood pressure lowering property or the negative inotropic effect). In patients with angina pectoris the most common coexisting cardiovascular risk factor is hypertension and, therefore, dihydropyridines or other calcium channel blockers (diltiazem or verapamil) have a role in combined treatment with or as a substitute for beta blockers.

\subsubsection{Nitrates}

Nitrates are indirect nitric oxide donors, which block calcium entry in smooth muscle cells and promote their relaxation through production of cyclic guanosine monophosphate (cGMP). Their main haemodynamic effect is to reduce preload by venodilatation, although at high doses they have an arterial vasodilating effect, causing dilatation of the epicardial arteries. Nitrates are usually well tolerated, although they may cause headaches, restricting their use. Because of their vasodilating action, they increase heart rate and it is recommended to combine them with preventative treatments such as beta-blockers, ivabradine or calcium channel blockers, which have a heart rate-lowering effect.

\subsubsection{Trimetazidine}

Trimetazidine has a complex antianginal mechanism of action. It acts mostly as a metabolic modulator, which optimizes myocardial energy expenditure on effort by promoting myocardial glucose use to the detriment of that of fats.

\subsubsection{Ranolazine}

Ranolazine $\left(\operatorname{Ranexa}^{\circledR}\right)$ is a novel antianginal agent (a piperazine derivative) shown to exert anti-ischemic effects without causing significant bradycardia or hypotension [22-25]. 
The drug reduces ischemia via inhibition of the late phase of the inward sodium current (late $\mathrm{I}_{\mathrm{Na}}$ ) during cardiac repolarization [26], with a consequent reduction in intracellular sodium and calcium overload which could contribute to its therapeutic effect. The drug was approved in 2006 in the US for use in management of chronic angina pectoris. Ranolazine is useful in patients who have not achieved an adequate response with other antianginal medications, and is used in combination with amlodipine, ß-blockers, or nitrates.

In addition, ranolazine has been proposed to possess antiarrhythmic potential [26-45] which was principally related to the inhibition of sodium current $\left(\mathrm{I}_{\mathrm{Na}}\right)$, rapid delayed rectifier potassium current $\left(\mathrm{I}_{\mathrm{Kr}}\right)$ and calcium current $\left(\mathrm{I}_{\mathrm{Ca}}\right)$ [27, 46-50]. A suppression of ventricular tachycardias by ranolazine after non-ST-segment elevation myocardial infarction has been proven in the MERLIN-TIMI 36 trial [51]. Experimental models and clinical reports have revealed an antiarrhythmic potential of ranolazine also in long QT syndrome [28, 48, 52-57]. Ranolazine has been associated with good safety profile during clinical usage. The side-effects are mild and tolerable (e.g. dizziness, nausea, constipation, headache).

\subsubsection{Ivabradine}

Ivabradine (Procoralan ${ }^{\circledR}$ ) is the only clinically available selective heart rate reducing agent and it exerts anti-ischaemic effects in patients with chronic stable angina [21]. Ivabradine inhibits the pacemaker $\left(\mathrm{I}_{\mathrm{f}}\right)$ current in the heart with reasonable selectivity [58] and with minimal effect on haemodynamic parameters [59]. According to the BEAUTIFUL (morBidity-mortality EvAlUaTion of the $\mathrm{I}_{\mathrm{f}}$ inhibitor ivabradine in patients with coronary disease and left ventricULar dysfunction) study, ivabradine can be used to reduce the incidence of coronary artery disease outcomes in a subgroup of patients who have heart rates of $70 \mathrm{bpm}$ or greater [60]. Ivabradine has been associated with a good safety profile during its clinical development [61]. In a trial, mild, tolerable visual symptoms (e.g. abrupt changes in light intensity) were reported as side effects [62]. Ivabradine is beneficial in patients with chronic stable angina pectoris equally to beta receptor blocker and calcium channel antagonist drugs [63]. Contrary to several heart ratereducing drugs, ivabradine lowers heart rate both at rest and during exercise without producing any negative inotropic or vasoconstrictor effect. The results of the recent SHIFT study support the significance of heart-rate reduction with ivabradine for improvement of clinical outcomes in heart failure and confirm the important role of heart rate in the 
pathophysiology of this disorder [64]. Improvement of regional myocardial blood flow and function and reduction of infarct size by ivabradine have also been described [65].

This selective heart rate reducing agent, lacking the negative inotropic effect, may offer a new therapeutic perspective in the treatment of ischaemic heart diseases e.g. in stable angina pectoris, particularly in patients with left ventricular dysfunction [66-72]. Based on the recent clinical trials and experiments, widening the indication of ivabradine for the treatment of heart failure or myocardial infarction is expected [73-86].

\subsection{Aims of the study}

The primary goal of the present study was to investigate in detail the cellular electrophysiological effects of ranolazine and ivabradine in dog and human heart preparations using conventional microelectrode technique. The effects of the drugs were mainly investigated in dog, a species resembling human in heart size, spontaneous frequency and repolarization. 


\section{MATERIALS AND METHODS}

\subsection{Dog cardiac tissues}

All experiments were carried out in compliance with the Guide for the Care and Use of Laboratory Animals (USA NIH publication No 85-23, revised 1985). The protocols were approved by the Department of Animal Health and Food Control of the Ministry of Agriculture and Rural Development, Hungary (15.1/01031/006/2008).

Adult mongrel dogs $(8-16 \mathrm{~kg}$ ) of either sex were used. Following anaesthesia (sodium pentobarbital, $30 \mathrm{mg} \cdot \mathrm{kg}^{-1}$ administered intravenously), the heart of each animal was rapidly removed through right lateral thoracotomy. The hearts were immediately rinsed in oxygenated Locke's solution containing (in $\mathrm{mM}$ ): $\mathrm{NaCl}, 120 ; \mathrm{KCl}, 4 ; \mathrm{CaCl}_{2}, 2$; $\mathrm{MgCl}_{2}, 1 ; \mathrm{NaHCO}_{3}, 22$; and glucose, 11 . The $\mathrm{pH}$ of this solution was 7.35 to 7.45 when gassed with $95 \% \mathrm{O}_{2}$ and $5 \% \mathrm{CO}_{2}$ at $37^{\circ} \mathrm{C}$. Papillary muscles were obtained from the right ventricle, and free-running Purkinje fibres (false tendons) were isolated from both ventricles of the hearts. The preparations were placed in a tissue bath and allowed to equilibrate for at least 1 hour while superfused with oxygenated Locke's solution (flow rate $4-5 \mathrm{ml} \cdot \mathrm{min}^{-1}$ ) warmed to $37^{\circ} \mathrm{C}$. To obtain midmyocardial ventricular preparations a piece from the basal part of the left ventricle was glued with tissue adhesive directly to top of the cutting stage of a vibratome (Vibratome 3000 PELCO 100 Vibratome Sectioning System). Tangential slices were cut in cold $\left(4^{\circ} \mathrm{C}\right)$ Locke's solution with a steel blade. The slices were placed in a preincubation chamber filled with oxygenated Locke's solution at room temperature for at least 3 hours.

Papillary muscles and midmyocardial preparations were initially stimulated (HSE [Hugo Sachs Elektronik] stimulator type 215/II, March-Hugstetten, Germany) at a basic cycle length of $1000 \mathrm{~ms}$, using $2 \mathrm{~ms}$ rectangular constant voltage pulses (twice diastolic threshold in intensity) isolated from ground and delivered across bipolar platinum electrodes in contact with the preparation. Purkinje fibres and atrial preparations (trabecules from the free wall of the right atria) were stimulated at the basic cycle length of $500 \mathrm{~ms}$. Each preparation was allowed to equilibrate for at least 1 hour while they were continuously superfused with Locke's solution. Temperature of the superfusate was kept constant at $37^{\circ} \mathrm{C}$. 
To obtain tachypacing induced remodelled dog atrial preparations (used as an established model for mimicing the pathological tissue in atrial fibrillation), beagle dogs (12-16 kg) were subjected to implantation of two pacemakers (Biotronik, Berlin, Germany) with pacemaker electrodes placed into the right atrium and into the right ventricle. Radiofrequency catheter ablation of the AV node was performed to avoid high atrial pacing rates propagating into the ventricles. The ventricular pacemaker was set to between 80 to 90 beat $\mathrm{min}^{-1}$, mimicking the baseline heart rate of the dog before the operation. Following recovery from surgery (3 days), high frequency right atrial pacing was started at 400 beat $\min ^{-1}$ and was maintained for at least 4 weeks before the experiments started to allow full electrical remodelling of the atria. Electrical remodelling [87] was confirmed by measuring atrial effective refractory period (i.e. AERP $<80 \mathrm{~ms}$ ) and atrial fibrillation inducibility (by 800/min right atrial pacing bursts) in vivo in conscious dogs.

\subsection{Human cardiac tissues}

Non-diseased human hearts that were technically unusable for transplantation (based on logistical, not patient-related, considerations) were obtained from general organ donors. Before cardiac explanation, organ donor patients did not receive medication except dobutamine, furosemide and plasma expanders. The investigations conform to the principles outlined in the Declaration of Helsinki of the World Medical Association. All experimental protocols were approved by the Scientific and Research Ethical Committee of the Medical Scientific Board at the Hungarian Ministry of Health (ETT-TUKEB), under ethical approval No 4991-0/2010-1018EKU (339/PI/010). Human cardiac tissue was stored in cardioplegic solution at $4^{\circ} \mathrm{C}$ for $4-8$ hours. Papillary muscles were obtained from the right ventricle. Preparations were initially stimulated at a basic cycle length of $1000 \mathrm{~ms}$ and allowed at least 1 hour to equilibrate while they were continuously superfused with Locke's solution. Temperature of the superfusate was kept constant at $37^{\circ} \mathrm{C}$.

\subsection{Conventional microelectrode technique}

Transmembrane potentials were recorded using conventional microelectrode technique as described earlier in detail [2]. Microelectrodes filled with $3 \mathrm{M} \mathrm{KCl}$ and having tip resistances of 5-15 MOhm were connected to the input of a high impedance electrometer (Experimetria microelectrode amplifier type 309, Budapest, Hungary), which was connected to ground. The voltage outputs from all amplifiers were displayed on a dual beam memory oscilloscope (Hitachi oscilloscope V-555, Japan). 
The maximum diastolic potential, action potential amplitude, maximum rate of depolarization $\left(\mathrm{V}_{\max }\right.$, equivalent to the $\left.\mathrm{dV} / \mathrm{dt}_{\max }\right)$ and APD measured at $50 \%$ and $90 \%$ repolarization $\left(\mathrm{APD}_{50-90}\right)$ were obtained, using a software developed in our Department (APES) on an IBM personal computer connected to the digital output of the oscilloscope. Impulse conduction time (CT) was measured as the time difference between the end of the stimulus artefact and the midtime of the upstroke of the action potential.

The following types of stimulation were applied in the course of the experiments: stimulation with a constant cycle length of $1000 \mathrm{~ms}$; stimulation with different constant cycle lengths ranging from 300 to $5000 \mathrm{~ms}$ (or to $2000 \mathrm{~ms}$ in the case of Purkinje fibres to prevent spontaneous diastolic depolarization). To determine the recovery kinetics of $\mathrm{V}_{\max }$, extra test action potentials were elicited by using single test pulses $\left(S_{2}\right)$ in a preparation driven at a basic cycle length of $400 \mathrm{~ms}$. The $S_{1}-S_{2}$ interval was increased progressively from the end of the refractory period. The effective refractory period was defined as the longest $S_{1}-S_{2}$ interval at which $S_{2}$ failed to elicit a propagated response. The diastolic intervals preceding the test action potential were measured from the point corresponding to $90 \%$ of repolarization of the preceding basic beat to the upstroke of the test action potential and were increased progressively. To determine the onset kinetics the preparations were continuously stimulated at cycle length of $1000 \mathrm{~ms}$, the stimulation was interrupted for 1 min, and then a train of 40-beat stimuli was applied with a cycle length of $400 \mathrm{~ms}$. Control recordings were obtained after equilibrium period. The effects of ivabradin and ranolazine were determined at the given concentrations, with recordings started 30 minutes after the addition of each concentration of the drug in a cumulative manner.

\subsection{Drugs}

Ranolazine and ivabradine (Sequoia Research Products Ltd, Pangbourne, United Kingdom) were dissolved in distilled water at stock solution concentration of 1 or $10 \mathrm{mM} \cdot \mathrm{L}^{-1}$. The stock solution was further diluted in the tissue bath to obtain the desired final drug concentrations. These stock solutions were stored at $4{ }^{\circ} \mathrm{C}$.

\subsection{Statistics}

Statistical analysis was performed using one way repeated measures analysis of variance (ANOVA) followed by Tukey's test, taking $\mathrm{P}<0.05$ as significant. Post hoc tests were done only in case of significant $\mathrm{F}$ value. Data are expressed as mean \pm standard error of the mean (S.E.M.). 


\section{RESULTS}

\subsection{Effects of ranolazine on transmembrane action potentials}

\subsubsection{Dog Purkinje fibre}

Ranolazine (dose- and rate-dependently) decreased the maximum rate of rise of the action potential upstroke $\left(\mathrm{V}_{\max }\right)$ in isolated dog cardiac Purkinje fibres (Fig. 2B). Action potential duration measured at $50 \%$ and $90 \%$ of repolarization $\left(\mathrm{APD}_{50}, \mathrm{APD}_{90}\right)$ was shortened in a concentration-dependent manner at pacing with a constant cycle length of $500 \mathrm{~ms}$ (Fig. 2A and Table 2). The reduction of $\mathrm{APD}_{50}$ was more pronounced than that of $\mathrm{APD}_{90}$ which resulted in an action potential with a triangular shape (Fig. 2A). The depression of $\mathrm{V}_{\max }$ evoked by ranolazine was strongly dependent upon stimulation frequency ("use-dependency"); i.e., as pacing cycle length was decreased, the depression of $\mathrm{V}_{\max }$ was increased. The block was statistically significant only at stimulation rates faster or equal of $2 \mathrm{~Hz}$ (Fig. 2B).

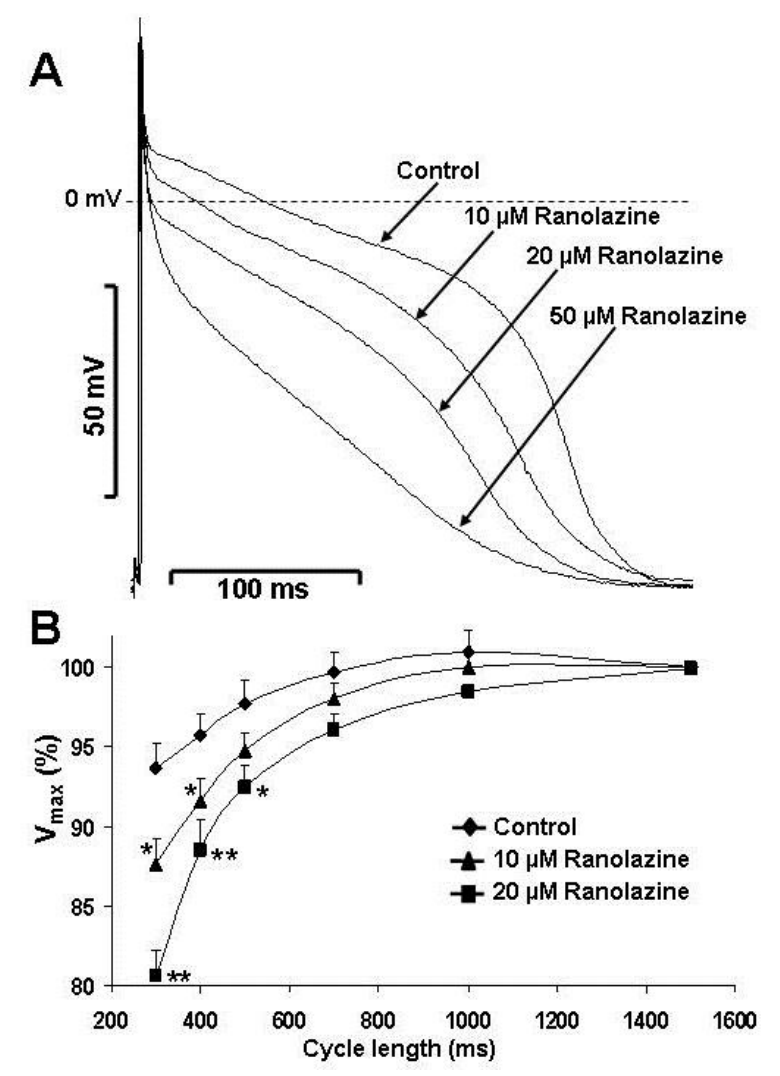

Fig. 2: Effect of ranolazine on the action potential waveform (A, representative figure) and on the maximum rate of depolarization $(B)$ in dog Purkinje fibre. The dotted line represents the zero voltage level. Voltage and time calibrations for the action potential recordings are indicated on the left. Values were expressed as percentage of $V_{\max }$ measured at cycle length of $1500 \mathrm{~ms}$. Results are mean \pm S.E.M. $* P<0.05$ and $* * P<$ 0.01 vs control, $n=11$. 
Table 2: The electrophysiological effects of ranolazine in dog Purkinje fibre at basic cycle length of $500 \mathrm{~ms}$.

\begin{tabular}{cccccc}
\hline Purkinje fibre & $M D P(\mathrm{mV})$ & $A P A(\mathrm{mV})$ & $A P D_{50}(\mathrm{~ms})$ & $A P D_{90}(\mathrm{~ms})$ & $V_{\max }\left(\mathrm{Vs}^{-1}\right)$ \\
\hline $\begin{array}{c}\text { Control } \\
\text { Ranolazine }\end{array}$ & $-86.9 \pm 0.8$ & $127.2 \pm 1.2$ & $174.8 \pm 9.2$ & $238.7 \pm 10.4$ & $669.7 \pm 27.2$ \\
$\quad-85.5 \pm 0.3$ & $125.6 \pm 1.4$ & $138.6 \pm 4.8^{\mathrm{b}}$ & $215.4 \pm 7.1^{\mathrm{b}}$ & $634.7 \pm 22.7$ \\
$\begin{array}{c}\text { Ranolazine } \\
20 \mu \mathrm{M}\end{array}$ & $-85.0 \pm 0.5$ & $123.3 \pm 1.3^{\mathrm{a}}$ & $111.7 \pm 5.6^{\mathrm{b}}$ & $203.9 \pm 5.8^{\mathrm{b}}$ & $584.6 \pm 20.2^{\mathrm{b}}$ \\
$\begin{array}{c}\text { Ranolazine } \\
50 \mu \mathrm{M}\end{array}$ & $-85.9 \pm 0.5$ & $122.2 \pm 1.6^{\mathrm{b}}$ & $79.7 \pm 7.0^{\mathrm{b}}$ & $192.6 \pm 4.2^{\mathrm{b}}$ & $548.4 \pm 14.8^{\mathrm{b}}$ \\
\hline
\end{tabular}

MDP, maximum diastolic potential; APA, action potential amplitude; $A P D_{50}$ and $A P D_{90}$, action potential durations at $50 \%$ and $90 \%$ of repolarization; $V_{\max }$, maximum rate of depolarization. Results are mean \pm S.E.M. ${ }^{a} P<0.05$ and ${ }^{b} P<0.01$ vs control. $n=11$ for 10 and $20 \mu M, n=9$ for $50 \mu M$.

\subsubsection{Dog papillary muscle}

In dog right ventricular papillary muscle at a stimulation cycle length of $1000 \mathrm{~ms}$ ranolazine exerted no statistically significant effect on action potential duration (Fig. 3A and Table 3). Ranolazine decreased the $\mathrm{V}_{\max }$ and increased the impulse conduction time (CT) dose- and rate-dependently (Fig. 3B and C). This effect was significant also at the concentration of $5 \mu \mathrm{M}$ at basic cycle length of $300-500 \mathrm{~ms}$. The decrease in $\mathrm{V}_{\max }$ was more pronounced in case of elevating potassium concentration from 4 to $6 \mathrm{mM}$ (Fig. $4 \mathrm{~A}$ and $\mathrm{B}$ ) and produced a shift in the normalized $\mathrm{V}_{\max }$-membrane potential curve to more negative potentials (Fig. 4C).

Table 3: The electrophysiological effects of ranolazine in dog papillary muscle at basic cycle length of $1000 \mathrm{~ms}$.

\begin{tabular}{cccccc}
\hline $\begin{array}{c}\text { Papillary } \\
\text { muscle }\end{array}$ & MDP $(\mathrm{mV})$ & $A P A(\mathrm{mV})$ & $A P D_{50}(\mathrm{~ms})$ & $A P D_{90}(\mathrm{~ms})$ & $V_{\max }\left(V s^{-1}\right)$ \\
\hline $\begin{array}{c}\text { Control } \\
\text { Ranolazine } \\
10 \mu \mathrm{M}\end{array}$ & $-84.2 \pm 0.6$ & $105.0 \pm 2.2$ & $178 . .0 \pm 9.2$ & $219.1 \pm 10.1$ & $258.0 \pm 9.2$ \\
$\begin{array}{c}\text { Ranolazine } \\
20 \mu \mathrm{M}\end{array}$ & $-84.0 \pm 0.5$ & $103.7 \pm 2.4$ & $175.2 \pm 7.2$ & $218.2 \pm 8.0$ & $233.9 \pm 9.4$ \\
\hline
\end{tabular}

MDP, maximum diastolic potential; $A P A$, action potential amplitude; $A P D_{50}$ and $A P D_{90}$, action potential durations at $50 \%$ and $90 \%$ of repolarization; $V_{\max }$, maximum rate of depolarization. Results are mean \pm S.E.M. ${ }^{a} P<0.05$ vs control. $n=9$. 


\section{B}
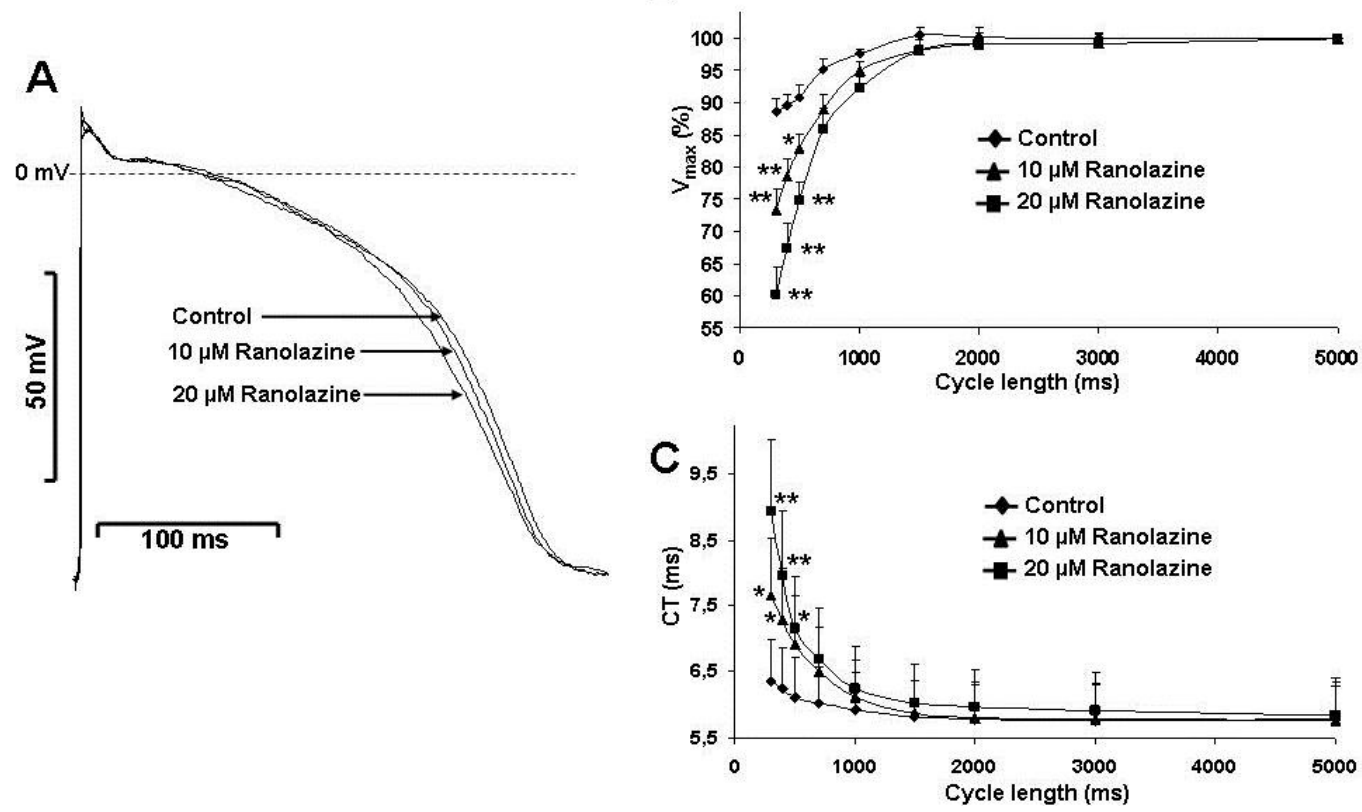

Fig. 3: Effect of ranolazine on the action potential waveform, maximum rate of depolarization and conduction time in dog papillary muscle. In panel A: effect of ranolazine on the action potential waveform. The dotted line represents the zero voltage level. Voltage and time calibrations for the action potential recordings are indicated on the left. In panel B: frequency dependent effect of ranolazine on maximum rate of depolarization $\left(V_{\max }\right)$ in dog papillary muscle. In panel $C$ : frequency dependent effect of ranolazine on conduction time $(C T)$ in dog papillary muscle. $V_{\text {max }}$ values were expressed as percentage of $V_{\max }$ measured at long $(5000 \mathrm{~ms})$ cycle length. Results are mean \pm S.E.M. * $P<0.05$ and $* * P<0.01$ vs control. $n=9$ for $B$ and $n=8$ for $C$.

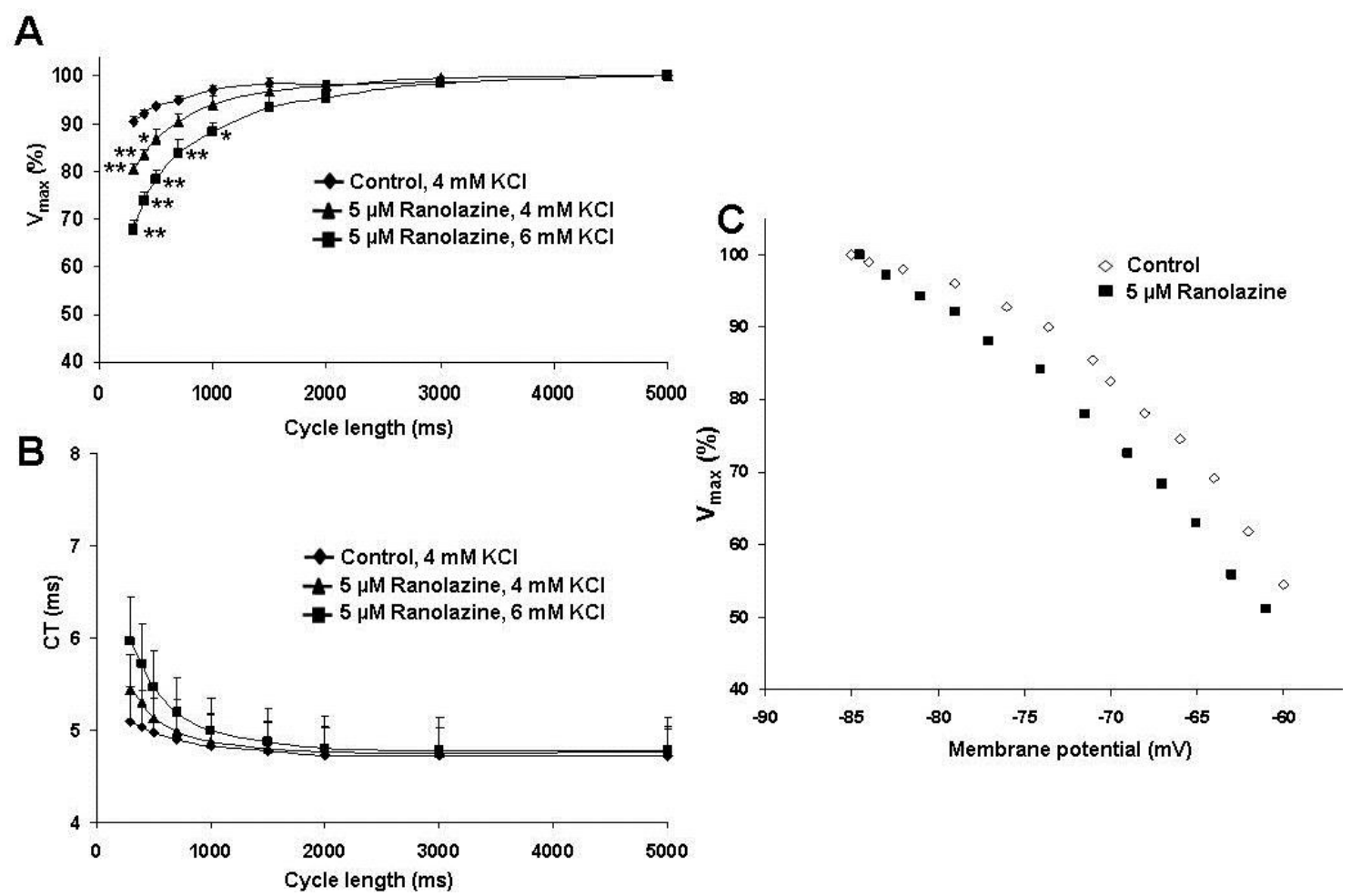

Fig. 4: Effect of $5 \mu M$ ranolazine in dog papillary muscle. In panel $A$ and B: frequency dependent effect of $5 \mu \mathrm{M}$ ranolazine in case of normal $(4 \mathrm{mM})$ and elevated $(6 \mathrm{mM})$ 
extracellular potassium concentration on maximum rate of depolarization $\left(V_{\max }\right)$ and on conduction time $(C T)$, respectively. $V_{\max }$ values were expressed as percentage of $V_{\max }$ measured at long $(5000 \mathrm{~ms})$ cycle length. Results are mean \pm S.E.M. In panel C: typical example of the effects of $5 \mu M$ ranolazine on the relationship between $V_{\max }$ and membrane potential at basic cycle length of $1000 \mathrm{~ms} . V_{\max }$ is plotted for control conditions and $5 \mu \mathrm{M}$ of ranolazine in the same experiment. $* P<0.05$ and $* * P<0.01$ vs control. $n=7$ for $A$ and $B$.

\subsubsection{Human papillary muscle}

In human right ventricular papillary muscle ranolazine moderately shortened the APD in 2 out of 4 experiments at a stimulation cycle length of $1000 \mathrm{~ms}$. On average ranolazine exerted no statistically significant effect on APD (Fig. 5A and Table 4). Ranolazine dose- and rate-dependently decreased the $\mathrm{V}_{\max }$ (Fig. 5B). In human preparations pronounced biphasic effect was evident during the incubation, i.e. first shortening (faster development of late sodium channel block) and later prolongation of APD (formation of $\mathrm{I}_{\mathrm{Kr}}$ block) was detected (Fig. 5C) suggesting multiple ion channel block with different drug binding kinetics.
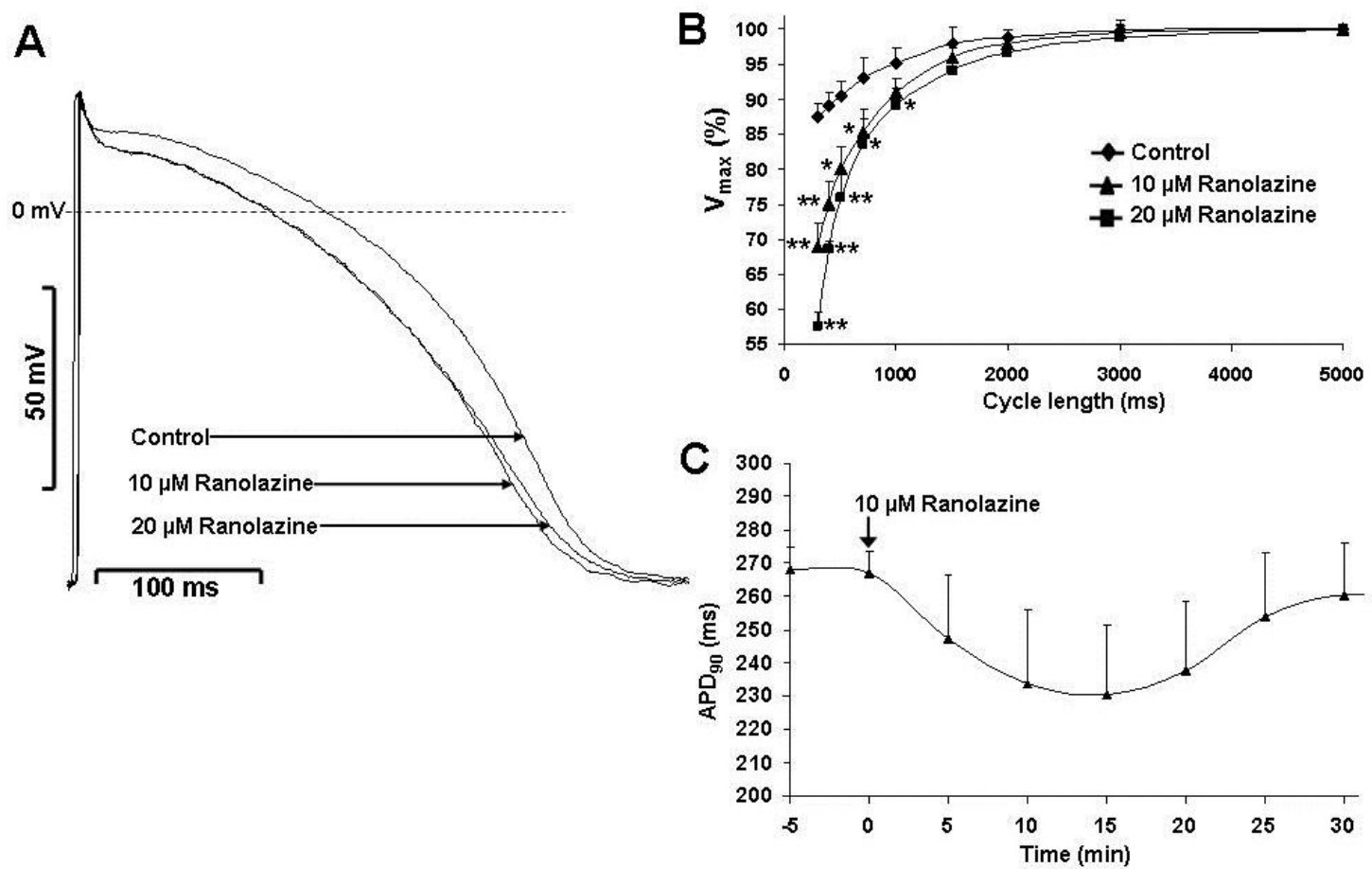

Fig. 5: Effect of ranolazine on the action potential waveform in human papillary muscle (A). The dotted line represents the zero voltage level. Voltage and time calibrations for the action potential recordings are indicated on the left. In panel B: frequency dependent effect of ranolazine on the maximum rate of depolarization $\left(V_{\max }\right)$ in human papillary muscle. Values were expressed as percentage of $V_{\max }$ measured at long $(5000 \mathrm{~ms}$ ) cycle length. In panel $C$ : biphasic effect of ranolazine during the incubation on action potential duration at basic cycle length of $1000 \mathrm{~ms}$. Results are mean \pm S.E.M. $* P<0.05$ and $* * P$ $<0.01$ vs control. $n=4$ for $B$ and $n=3$ for $C$. 
Table 4: The electrophysiological effects of ranolazine in human papillary muscle at basic cycle length of $1000 \mathrm{~ms}$.

\begin{tabular}{cccccc}
\hline $\begin{array}{c}\text { Human papillary } \\
\text { muscle }\end{array}$ & MDP $(\mathrm{mV})$ & APA $(\mathrm{mV})$ & APD $D_{50}(\mathrm{~ms})$ & $A P D_{90}(\mathrm{~ms})$ & $V_{\max }\left(\mathrm{Vs}^{-1}\right)$ \\
\hline $\begin{array}{c}\text { Control } \\
\text { Ranolazine } \\
10 \mu \mathrm{M}\end{array}$ & $-85.3 \pm 0.4$ & $112.4 \pm 1.1$ & $230.0 \pm 22.9$ & $289.8 \pm 21.9$ & $318.0 \pm 8.8$ \\
$\begin{array}{c}\text { Ranolazine } \\
20 \mu \mathrm{M}\end{array}$ & $-85.8 \pm 1.6$ & $112.1 \pm 1.3$ & $210.5 \pm 29.6$ & $284.5 \pm 30.6$ & $309.1 \pm 27.5$ \\
\hline
\end{tabular}

MDP, maximum diastolic potential; $A P A$, action potential amplitude; $A P D_{50}$ and $A P D_{90}$, action potential durations at $50 \%$ and $90 \%$ of repolarization; $V_{\max }$, maximum rate of depolarization. Results are mean \pm S.E.M. ${ }^{a} P<0.05$ vs control. $n=4$.

\subsubsection{Onset and offset kinetics of $V_{\max }$ block}

In dog papillary muscles, after 1 minute of rest, train of stimuli driven at the cycle length of $400 \mathrm{~ms}$, the onset kinetics of $20 \mu \mathrm{M}$ ranolazine induced $\mathrm{V}_{\max }$ block was fitted by a single exponential, resulting in the onset rate kinetic constant of $\tau=3.5 \pm 0.8$ beat $^{-1}$ (Fig. $6 \mathrm{~A}$ ). At the same stimulation cycle length of $400 \mathrm{~ms}$, the recovery of $\mathrm{V}_{\max }$ (offset kinetics) during control was best fit to a single exponential relation. The time constant for recovery of $\mathrm{V}_{\max }$ during control was fast $\left(\tau_{\text {fast }}=35.7 \pm 5.4 \mathrm{~ms}\right.$ ) and before final repolarization of the basic action potential, it was almost complete. In the presence of $20 \mu \mathrm{M}$ ranolazine the recovery kinetics of $\mathrm{V}_{\max }$ was best fitted with a two exponential relation. In addition to a fast component $\left(\tau_{\text {fast }}=29.1 \pm 2.9 \mathrm{~ms}\right)$ which reflects recovery of the drug-free sodium channels [88], a slow component $\left(\tau_{\text {slow }}=1.58 \pm 0.25 \mathrm{~s}\right)$ of recovery of $\mathrm{V}_{\max }$ was revealed following exposure to ranolazine. This second slow component for recovery of $\mathrm{V}_{\max }$ may reflect effects on drug-affected sodium channels [88] (Fig. 6B). 

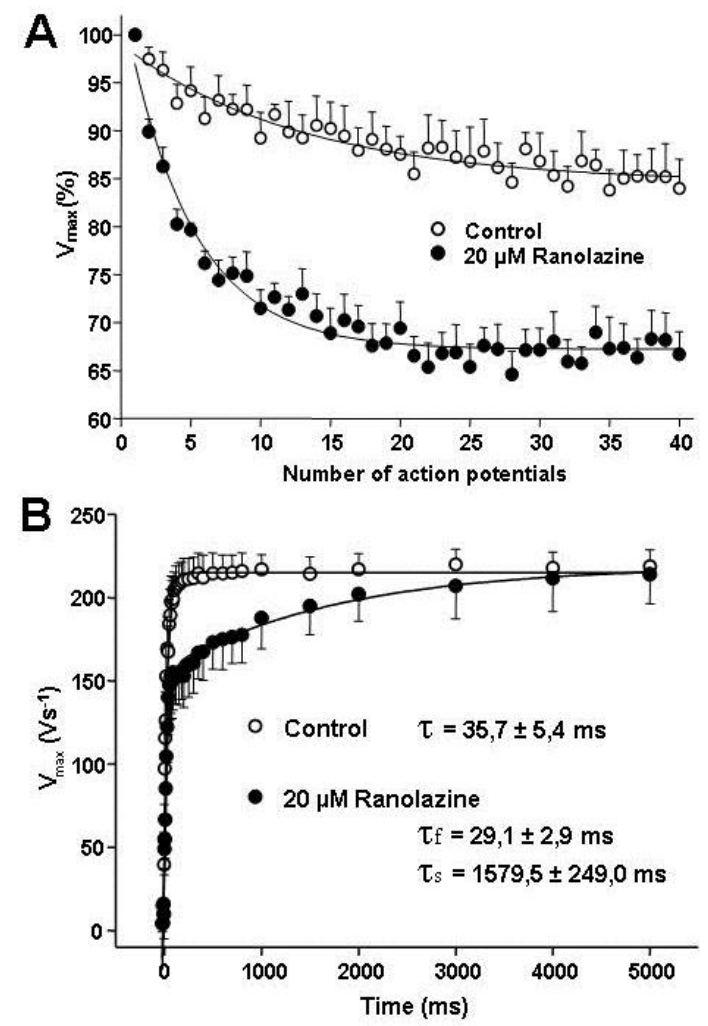

Fig. 6: Onset $(A)$ and offset $(B)$ kinetics of $V_{\max }$ block by ranolazine in dog papillary muscle at basic cycle length of $400 \mathrm{~ms}$. $\tau_{f}$ : time constant of the fast component $\tau_{s}$ : time constant of the slow component. Results are mean \pm S.E.M. $n=9$ for $A, n=8$ for $B$.

\subsubsection{Dog midmyocardial preparations}

In dog midmyocardial tissue (M-cells) $10 \mu \mathrm{M}$ ranolazine exerted no significant effect on APD at basic cycle length of $1000 \mathrm{~ms}$, however, at higher concentration $(20 \mu \mathrm{M})$ it produced a slight prolongation of APD (Fig. 7 and Table 5). In these preparations ranolazine decreased the maximum rate of rise of the action potential upstroke $\left(\mathrm{V}_{\max }\right)$ which was significant only in higher concentration $(20 \mu \mathrm{M})$ at basic cycle length of 1000 ms (Table 5).

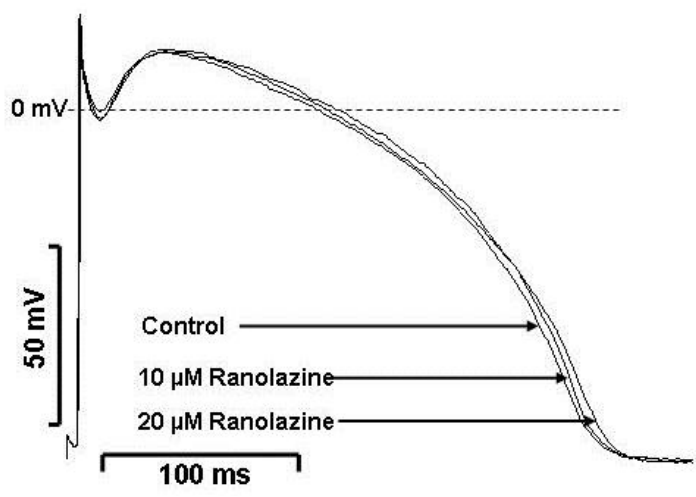

Fig. 7: Effect of ranolazine on the action potential waveform in dog midmyocardial heart slice at basic cycle length of $1000 \mathrm{~ms}$. The dotted line represents the zero voltage level. Voltage and time calibrations for the action potential recordings are indicated on the left. 
Table 5: The electrophysiological effects of ranolazine in dog midmyocardial preparation at basic cycle length of $1000 \mathrm{~ms}$.

\begin{tabular}{cccccc}
\hline M-cells & MDP $(\mathrm{mV})$ & $A P A(\mathrm{mV})$ & $A P D_{50}(\mathrm{~ms})$ & $A P D_{90}(\mathrm{~ms})$ & $V_{\max }\left(V s^{-1}\right)$ \\
\hline $\begin{array}{c}\text { Control } \\
\text { Ranolazine }\end{array}$ & $-84.5 \pm 0.6$ & $107.8 \pm 1.9$ & $206.2 \pm 11.6$ & $255.6 \pm 13.8$ & $328.6 \pm 20.2$ \\
$\quad 10 \mu \mathrm{M}$ & $-85.1 \pm 1.9$ & $105.4 \pm 2.8$ & $205.4 \pm 11.4$ & $257.0 \pm 13.5$ & $301.3 \pm 26.1$ \\
$\begin{array}{c}\text { Ranolazine } \\
20 \mu \mathrm{M}\end{array}$ & $-84.3 \pm 1.6$ & $106.3 \pm 2.3$ & $213.7 \pm 20.3$ & $271.8 \pm 24.2$ & $283.5 \pm 24.8^{\mathrm{a}}$ \\
\hline
\end{tabular}

$M D P$, maximum diastolic potential; $A P A$, action potential amplitude; $A P D_{50}$ and $A P D_{90}$, action potential durations at $50 \%$ and $90 \%$ of repolarization; $V_{\max }$, maximum rate of depolarization. Results are mean \pm S.E.M. ${ }^{a} P<0.05$ vs control. $n=7$.

\subsubsection{Dispersion of repolarization}

In dog heart ranolazine decreased the dispersion of repolarization i.e. the difference in $\mathrm{APD}_{90}$ values between Purkinje fibres and papillary muscles (Fig. 8). The drug produced abbreviation in APD of Purkinje fibre and at the same time exerted no significant effect on the subendocardial layers (papillary muscle).

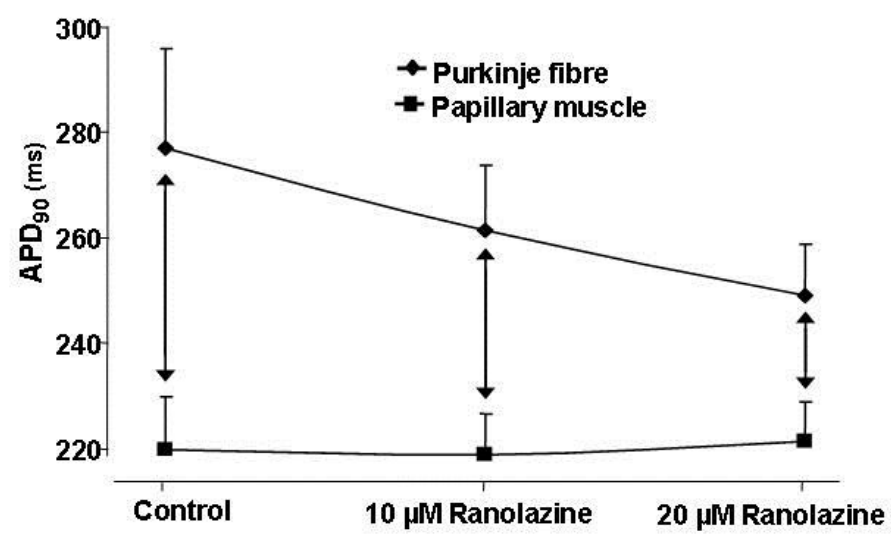

Fig. 8: Effect of ranolazine on dispersion of repolarization between dog Purkinje fibre and papillary muscle at basic cycle length of $1000 \mathrm{~ms}$. Results are mean \pm S.E.M. $n=11$ for Purkinje fibre and $n=9$ for papillary muscle.

\subsubsection{Dog atria}

In atria from dog in sinus rhythm (SR) a statistically significant prolongation of the APD was observed in the presence of $10 \mu \mathrm{M}$ ranolazine and this lengthening further 
increased at $20 \mu \mathrm{M}$ (Fig. 9A and 10). In addition, the drug exerted a marked and significant use-dependent depression of $\mathrm{V}_{\max }$ at basic cycle length of 300-700 ms (Fig. 9C). This block was significantly more expressed in atria than in ventricle at fast stimulation frequencies $(\mathrm{BCL}=300-400 \mathrm{~ms})$. In tachypacing induced remodelled dog atrial preparations ranolazine also produced statistically significant prolongation of $\mathrm{APD}_{90}$ with a concomittant shortening of $\mathrm{APD}_{50}$ (Fig. $9 \mathrm{~B}$ and 10). The repolarization $\left(\mathrm{APD}_{90}\right)$ lengthening and $\mathrm{V}_{\max }$ blocking effects were more pronounced in normal (healthy) atria $(\mathrm{SR})$, than in remodelled atria (AF).
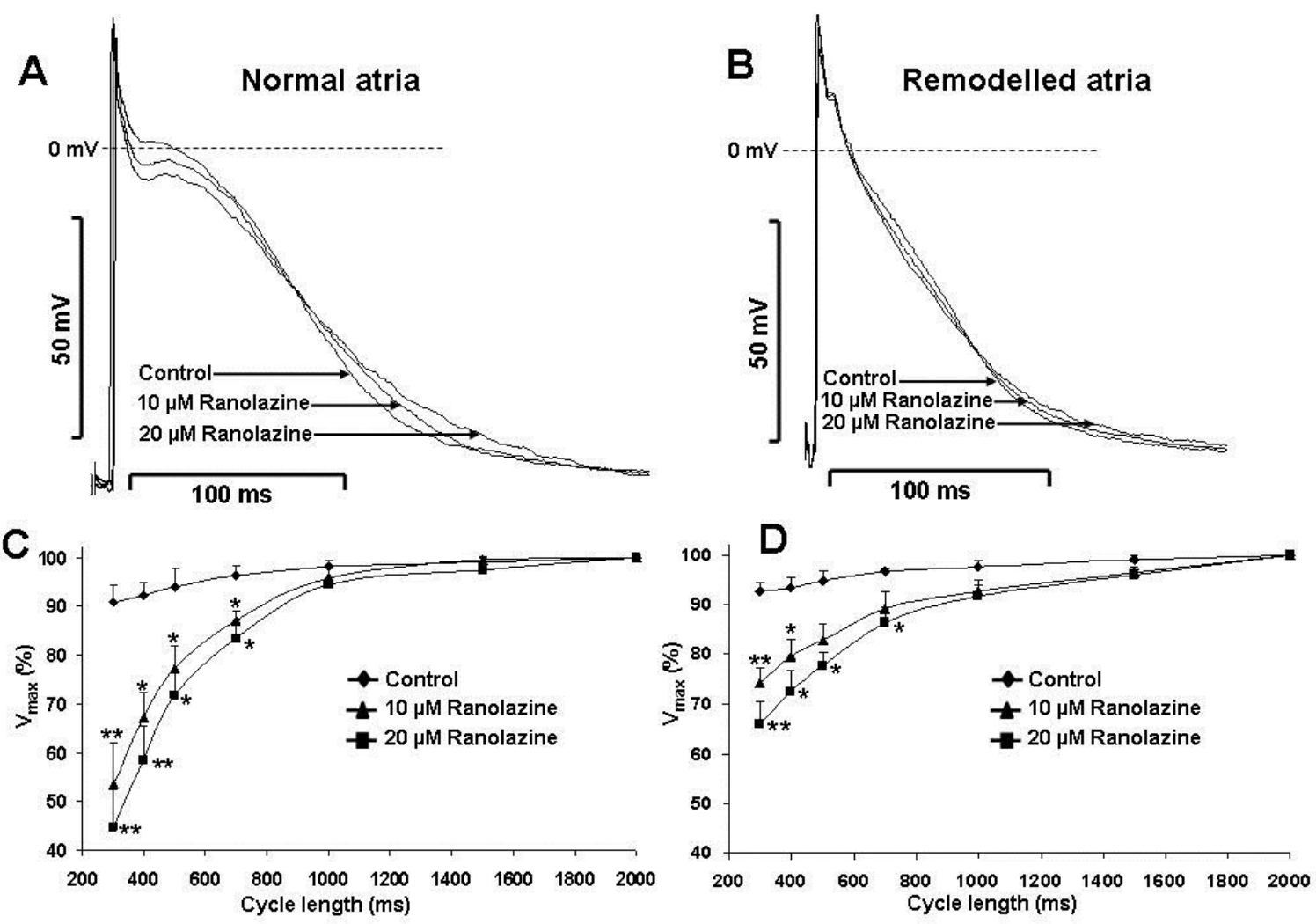

Fig. 9: Effect of ranolazine on the action potential waveform at stimulation frequency of 2 $\mathrm{Hz}$ in atria from dog in sinus rhythm (A) and tachypacing induced remodelled dog atrial preparations $(B)$. In pane $C$ and $D$ : frequency dependent effect of ranolazine on maximum rate of depolarization $\left(V_{\max }\right)$ in atria from dog in sinus rhythm and tachypacing induced remodelled dog atrial preparations, respectively. $V_{\max }$ values were expressed as percentage of $V_{\max }$ measured at long $(2000 \mathrm{~ms})$ cycle length. The dotted line represents the zero current level. Voltage and time calibrations for the action potential recordings are indicated on the left of the figure. Results are mean \pm S.E.M. $* P<0.05$ and $* * P<0.01$ vs control. $n=5$ for $C$ and $n=4$ for $D$. 


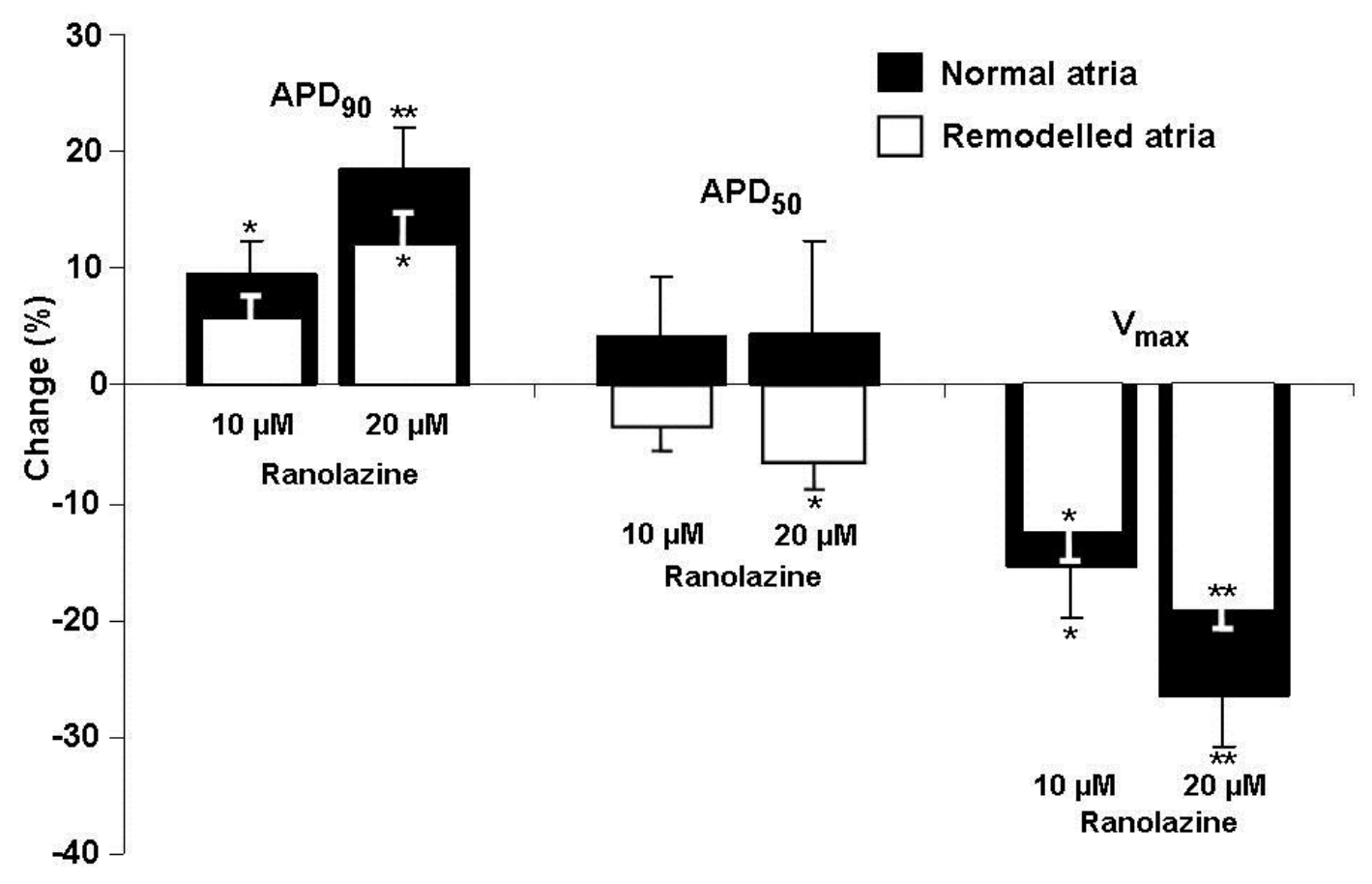

Fig. 10: The electrophysiological effects of ranolazine in atria from dog in sinus rhythm and tachypacing induced remodelled dog atrial preparations at basic cycle length of 500 ms. Results are mean \pm S.E.M. $* P<0.05$ and $* * P<0.01$ vs control. $n=5$ for both groups.

\subsection{Effects of ivabradine on transmembrane action potentials}

\subsubsection{Dog Purkinje fibre}

In dog Purkinje strands, stimulation was terminated to allow development of spontaneous activity. The developed spontaneous frequency in the control preparations was about $0.5 \mathrm{~Hz}$ (Fig. 11A). Ivabradine concentration-dependently decreased the steepness of spontaneous diastolic depolarization and slowed spontaneous rate of firing of the Purkinje fibres (Fig. 11B-D). Spontaneous activity was completely abolished by $10 \mu \mathrm{M}$ ivabradine in all preparations. In isolated dog Purkinje fibres ivabradine concentration- and rate-dependently decreased the maximum rate of rise of the action potential upstroke $\left(\mathrm{V}_{\max }\right)$, and action potential amplitude while action potential duration measured at $50 \%$ of repolarization was shortened in a concentration-dependent manner at pacing with a constant cycle length of $500 \mathrm{~ms}$ (Fig. 12 and Table 6). The depression of $\mathrm{V}_{\max }$ evoked by 1 and $10 \mu \mathrm{M}$ ivabradine was strongly dependent upon stimulation frequency ("usedependent"); i.e., as pacing cycle length was decreased, the depression of $\mathrm{V}_{\max }$ was increased. 

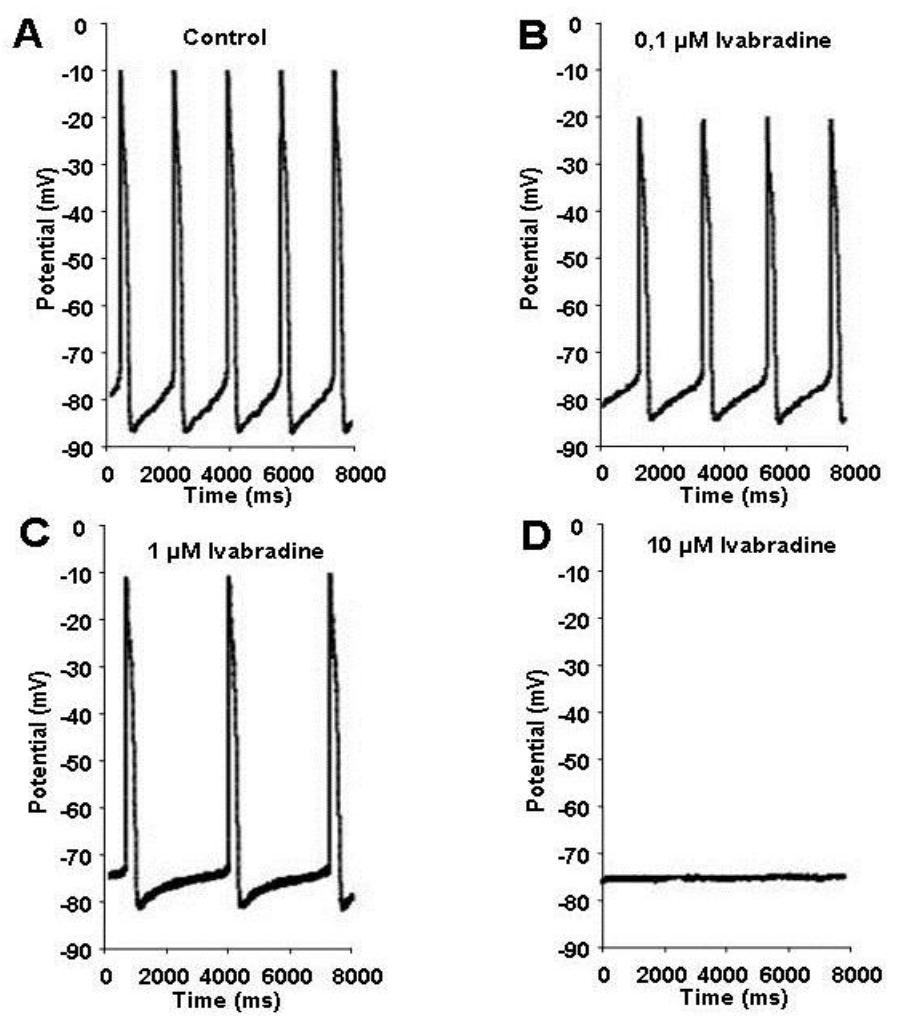

Fig. 11: Effect of ivabradine on the steepness of diastolic depolarization and spontaneous action potential firing in dog Purkinje fibre (representative figure). Cumulative drug application.
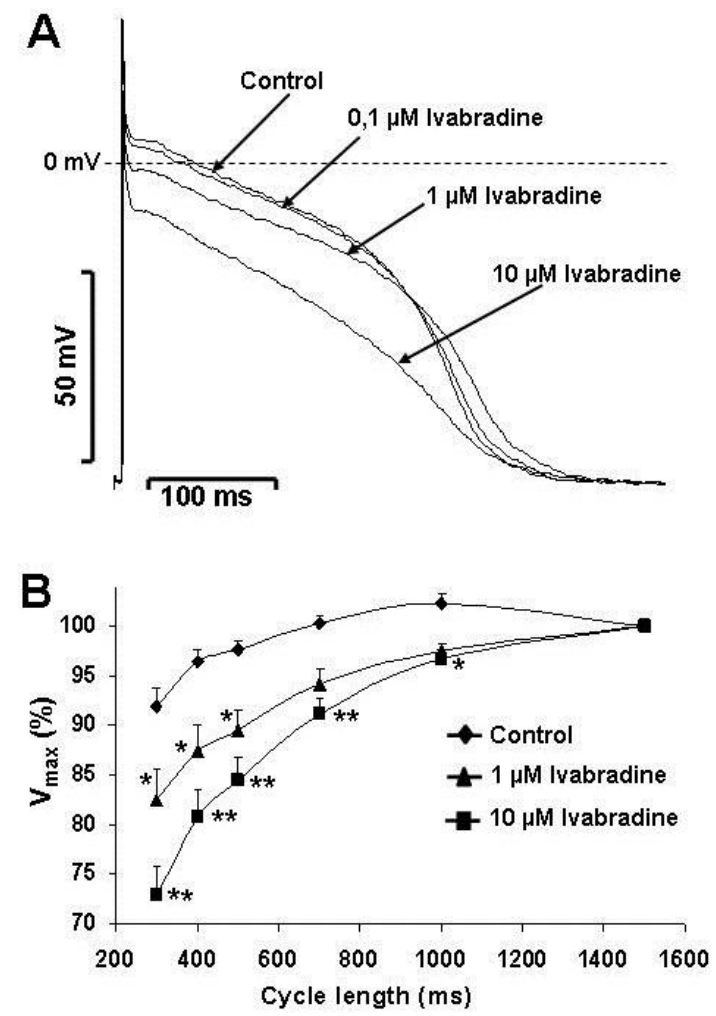

Fig. 12: Effect of ivabradine (A) on the action potential waveform and $(B)$ on the maximum rate of depolarization $\left(V_{\max }\right)$ in dog Purkinje fibre. The dotted line represents the zero voltage level. Voltage and time calibrations for the action potential recordings are indicated on the left. Values were expressed as percentage of $V_{\max }$ measured at cycle length of $1500 \mathrm{~ms}$. Results are mean \pm S.E.M. $* P<0.05$ and $* * P<0.01$ vs control, $n=10$. 
Table 6: The electrophysiological effects of ivabradine in dog Purkinje fibre at basic cycle length of $500 \mathrm{~ms}$.

\begin{tabular}{cccccc}
\hline Purkinje fibre & $M D P(\mathrm{mV})$ & $A P A(\mathrm{mV})$ & $A P D_{50}(\mathrm{~ms})$ & $A P D_{90}(\mathrm{~ms})$ & $V_{\max }\left(V s^{-1}\right)$ \\
\hline $\begin{array}{c}\text { Control } \\
\text { Ivabradine }\end{array}$ & $-88.3 \pm 1.0$ & $129.4 \pm 1.9$ & $170.0 \pm 9.8$ & $245.7 \pm 7.5$ & $640.7 \pm 38.4$ \\
$\begin{array}{c}1 \mu \mathrm{M} \\
\begin{array}{c}\text { Ivabradine } \\
10 \mu \mathrm{M}\end{array}\end{array}$ & $-88.5 \pm 1.5$ & $126.5 \pm 2.8$ & $165.8 \pm 8.8$ & $252.0 \pm 6.8$ & $556.8 \pm 42.8^{\mathrm{a}}$ \\
\hline
\end{tabular}

MDP, maximum diastolic potential; $A P A$, action potential amplitude; $A P D_{50}$ and $A P D_{90}$, action potential durations at $50 \%$ and $90 \%$ of repolarization; $V_{\max }$, maximum rate of depolarization. Results are mean \pm S.E.M. ${ }^{a} P<0.05$ vs control. $n=8$.

\subsubsection{Dog papillary muscle}

In dog right ventricular papillary muscle at a stimulation cycle length of $1000 \mathrm{~ms}$ ivabradine lengthened the action potential repolarization in a concentration dependent manner (Fig. 13A and Table 7). Ivabradine decreased the $\mathrm{V}_{\max }$ and increased the impulse conduction time (CT) dose- and rate-dependently (Fig. 13B and C).
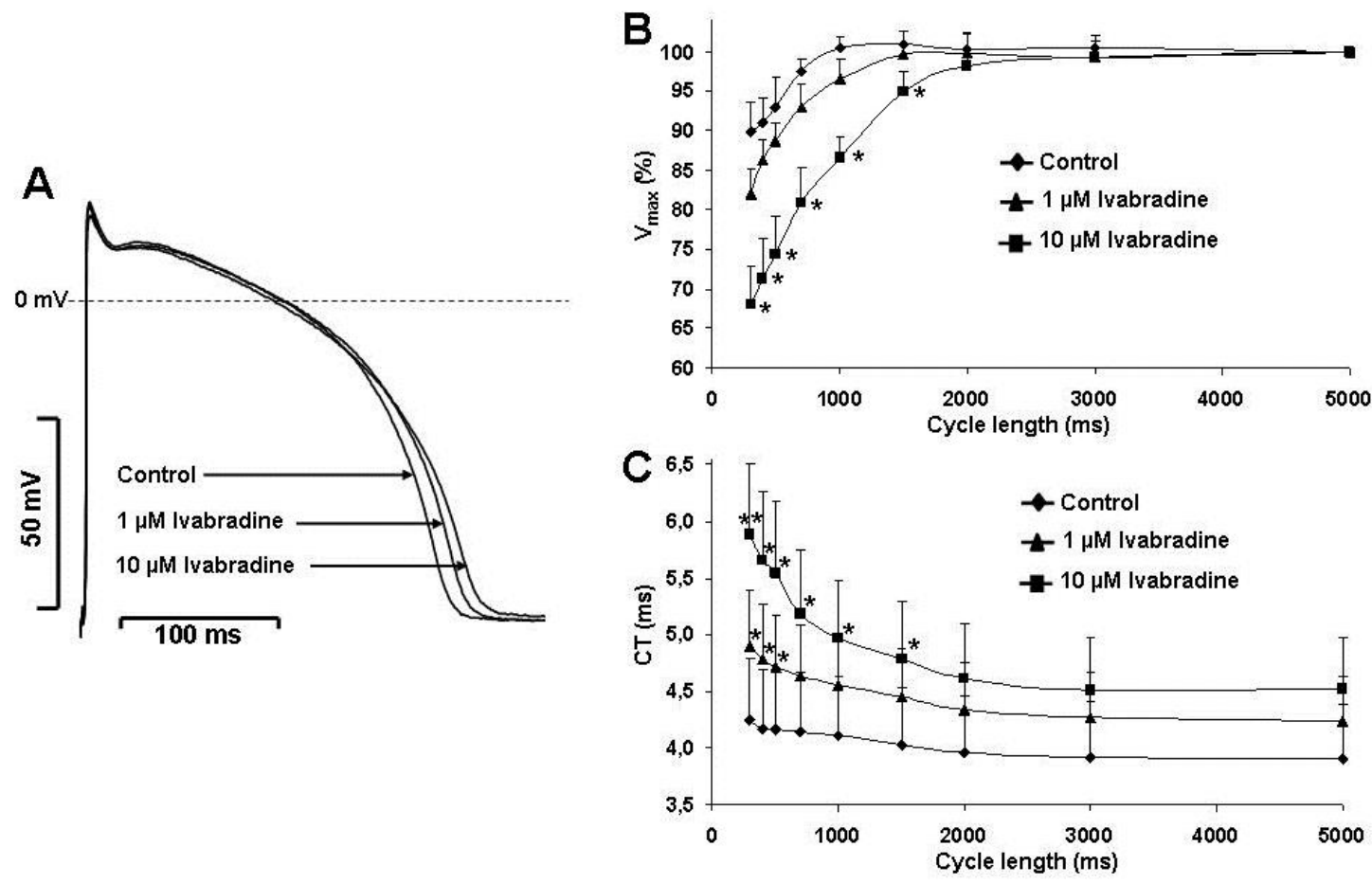

Fig. 13: Effect of ivabradine on the action potential waveform, maximum rate of depolarization and conduction time in dog papillary muscle. In panel A: effect of ivabradine on the action potential waveform. The dotted line represents the zero voltage level. Voltage and time calibrations for the action potential recordings are indicated on the left. In panel B: frequency dependent effect of ivabradine on maximum rate of depolarization $\left(V_{\max }\right)$ in dog papillary muscle. In panel $C$ : frequency dependent effect of ivabradine on conduction time $(C T)$ in dog papillary muscle. $V_{\text {max }}$ values were expressed as percentage of $V_{\max }$ measured at long $(5000 \mathrm{~ms})$ cycle length. Results are mean \pm S.E.M. $* P<0.05$ and $* * P<0.01$ vs control. $n=8$ for $B$ and $C$. 
Table 7: The electrophysiological effects of ivabradine in dog papillary muscle at basic cycle length of $1000 \mathrm{~ms}$.

\begin{tabular}{cccccc}
\hline Papillary muscle & MDP $(\mathrm{mV})$ & APA $(\mathrm{mV})$ & $A P D_{50}(\mathrm{~ms})$ & $A P D_{90}(\mathrm{~ms})$ & $V_{\max }\left(V s^{-1}\right)$ \\
\hline $\begin{array}{c}\text { Control } \\
\begin{array}{c}\text { Ivabradine } \\
1 \mu \mathrm{M}\end{array}\end{array}$ & $-86.3 \pm 1.2$ & $106.5 \pm 1.5$ & $190.1 \pm 4.1$ & $223.9 \pm 5.9$ & $201.1 \pm 17.2$ \\
$\begin{array}{c}\text { Ivabradine } \\
10 \mu \mathrm{M}\end{array}$ & $-87.6 \pm 1.1$ & $106.1 \pm 2.4$ & $205.0 \pm 5.0^{\mathrm{b}}$ & $243.8 \pm 6.5^{\mathrm{b}}$ & $181.8 \pm 20.3$ \\
\hline
\end{tabular}

MDP, maximum diastolic potential; APA, action potential amplitude; $A P D_{50}$ and $A P D_{90}$, action potential durations at $50 \%$ and $90 \%$ of repolarization; $V_{\max }$, maximum rate of depolarization. Results are mean \pm S.E.M. ${ }^{a} P<0.05$ and $^{b} P<0.01$ vs control. $n=8$.

The drug moderately prolonged the APD in case of normal repolarization reserve, while after attenuation of the repolarization reserve by inhibition of the inward rectifier potassium current by adding $30 \mu \mathrm{M} \mathrm{BaCl}_{2}$ it further lengthened the ventricular repolarization (Fig. 14).
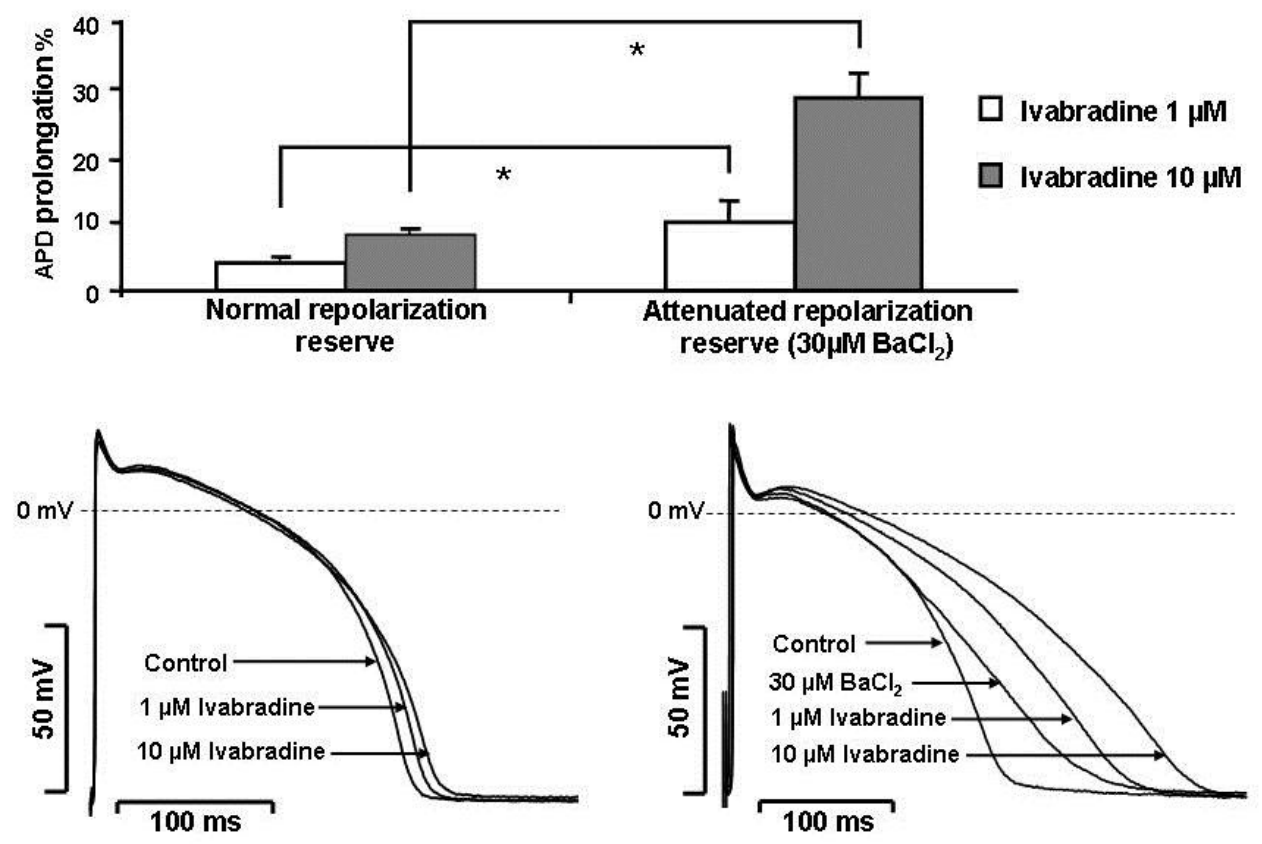

Fig. 14: Effect of ivabradine on action potential duration of dog papillary muscle with normal and attenuated repolarization reserve at stimulation cycle length of $1000 \mathrm{~ms}$. Results are mean \pm S.E.M. $n=8$ for normal and $n=5$ for attenuated repolarization reserve.

\subsubsection{Human papillary muscle}

In human ventricular muscle preparations at a stimulation cycle length of $1000 \mathrm{~ms}$ $1 \mu \mathrm{M}$ ivabradine did not change ventricular repolarization and a small, but significant prolongation of the action potential repolarization was observed only in the presence of 
high $(10 \mu \mathrm{M})$ concentration of ivabradine (Fig. 15A and Table 8). Ivabradine dose- and rate-dependently decreased the $\mathrm{V}_{\max }$ and increased the impulse conduction time (Fig. 15B and C).
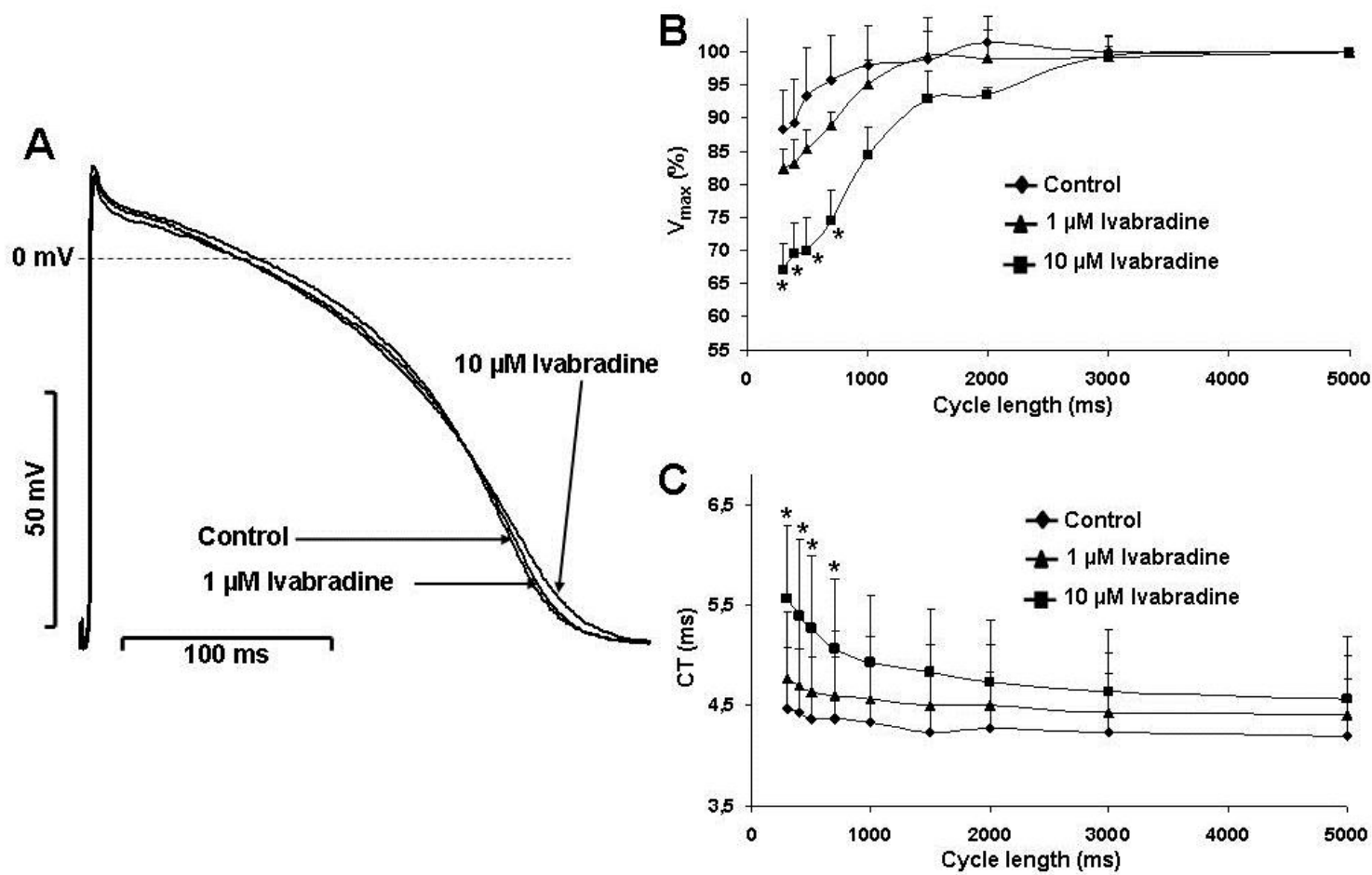

Fig. 15: Effect of ivabradine on the action potential waveform, maximum rate of depolarization and conduction time in human papillary muscle. In panel A: effect of ivabradine on the action potential waveform. The dotted line represents the zero voltage level. Voltage and time calibrations for the action potential recordings are indicated on the left. In panel $B$ : frequency dependent effect of ivabradine on maximum rate of depolarization $\left(V_{\max }\right)$ in human papillary muscle. In panel $C$ : frequency dependent effect of ivabradine on conduction time $(C T)$ in human papillary muscle. $V_{\max }$ values were expressed as percentage of $V_{\max }$ measured at long $(5000 \mathrm{~ms})$ cycle length. Results are mean \pm S.E.M. $* P<0.05$ vs control. $n=4$ for $B$ and $C$.

Table 8: The electrophysiological effects of ivabradine in human papillary muscle at basic cycle length of $1000 \mathrm{~ms}$.

\begin{tabular}{cccccc}
\hline $\begin{array}{c}\text { Human papillary } \\
\text { muscle }\end{array}$ & $M D P(\mathrm{mV})$ & $A P A(\mathrm{mV})$ & $A P D_{50}(\mathrm{~ms})$ & $A P D_{90}(\mathrm{~ms})$ & $V_{\max }\left(\mathrm{Vs}^{-1}\right)$ \\
\hline $\begin{array}{c}\text { Control } \\
\text { Ivabradine } \\
1 \mu \mathrm{M}\end{array}$ & $-85.4 \pm 0.7$ & $106.1 \pm 4.0$ & $181.1 \pm 15.8$ & $243.3 \pm 15.7$ & $278.4 \pm 24.3$ \\
$\begin{array}{c}\text { Ivabradine } \\
10 \mu \mathrm{M}\end{array}$ & $-85.5 \pm 0.5$ & $104.5 \pm 4.3$ & $187.7 \pm 15.9$ & $252.0 \pm 15.8$ & $266.3 \pm 32.4$ \\
\hline
\end{tabular}

MDP, maximum diastolic potential; $A P A$, action potential amplitude; $A P D_{50}$ and $A P D_{90}$, action potential durations at $50 \%$ and $90 \%$ of repolarization; $V_{\max }$, maximum rate of depolarization. Results are mean \pm S.E.M. ${ }^{a} P<0.05$ vs control. $n=6$. 


\subsubsection{Onset and offset kinetics of $V_{\text {max }}$ block}

In dog ventricular muscles driven at the cycle length of $400 \mathrm{~ms}$ the onset kinetics of $\mathrm{V}_{\text {max }}$ block induced by $10 \mu \mathrm{M}$ ivabradine was fitted to a single exponential, resulting in the onset rate kinetic constant of $\tau=13.9 \pm 3.2$ beat $^{-1}$ (Fig. 16A). In dog ventricular muscles at the stimulation cycle length of $400 \mathrm{~ms}$, the recovery of $\mathrm{V}_{\max }$ during control was best fit to a single exponential relation (Fig. 16B). The time constant for recovery of $\mathrm{V}_{\max }$ during control was fast $\left(\tau_{\text {fast }}=46.2 \pm 4.3 \mathrm{~ms}\right.$ ) and before final repolarization of the basic action potential, it was almost complete. In the presence of $10 \mu \mathrm{M}$ ivabradine the recovery kinetics of $\mathrm{V}_{\max }$ was best fit with a twoexponential relation. In addition to a fast component $\left(\tau_{\text {fast }}=41.2 \pm 8.2 \mathrm{~ms}\right)$ which reflects recovery of the drug-free sodium channels [88], a slow component $\left(\tau_{\text {slow }}=8.76 \pm 1.34 \mathrm{~s}\right)$ of recovery of $\mathrm{V}_{\max }$ was revealed following exposure to ivabradine. This second slow component for recovery of $\mathrm{V}_{\max }$ may reflect effects on drugaffected sodium channels [88] (Fig. 16B).

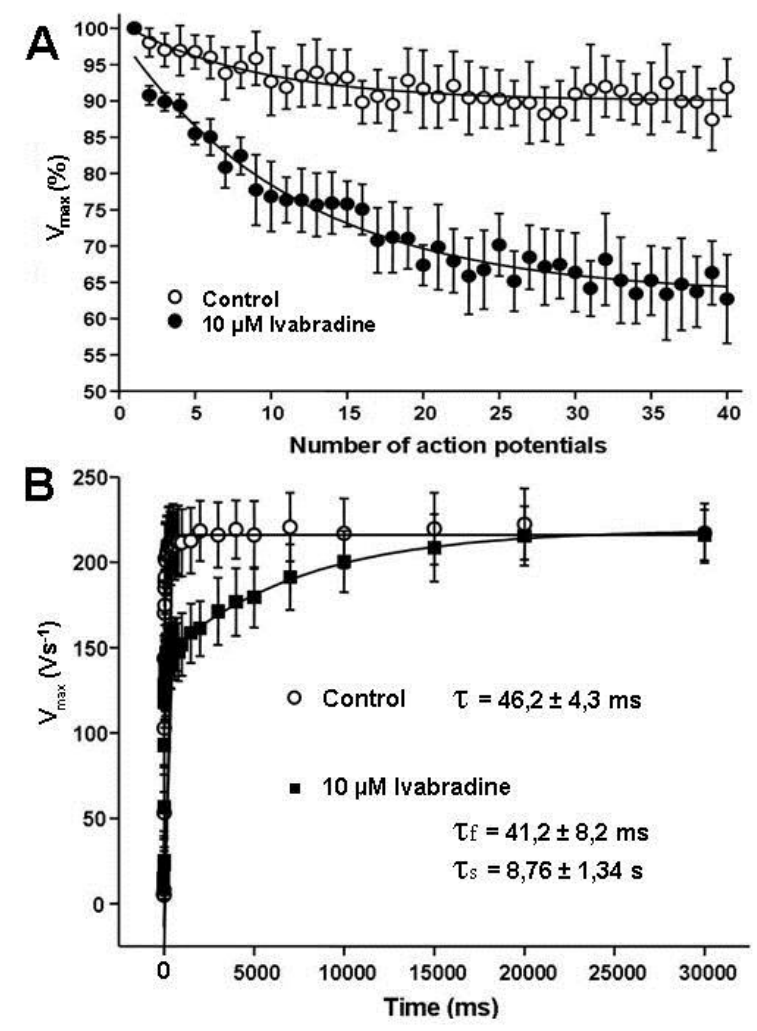

Fig. 16: Onset $(A)$ and offset $(B)$ kinetics of $V_{\max }$ block by ivabradine in dog right ventricular papillary muscle $(B C L=400 \mathrm{~ms}) . \tau_{f}$ : time constant of the fast component $\tau_{s}$ : time constant of the slow component. Results are mean \pm S.E.M. $n=7$ for $A, n=8$ for $B$. 


\subsubsection{Dispersion of repolarization}

In dog heart ivabradine preserved the dispersion of repolarization i.e. the difference in $\mathrm{APD}_{90}$ values between Purkinje fibres and papillary muscles (Fig. 17) at basic cycle length of $1000 \mathrm{~ms}$. The drug produced prolongation in APD of Purkinje fibre and exerted the same effect on the subendocardial layers (papillary muscle).

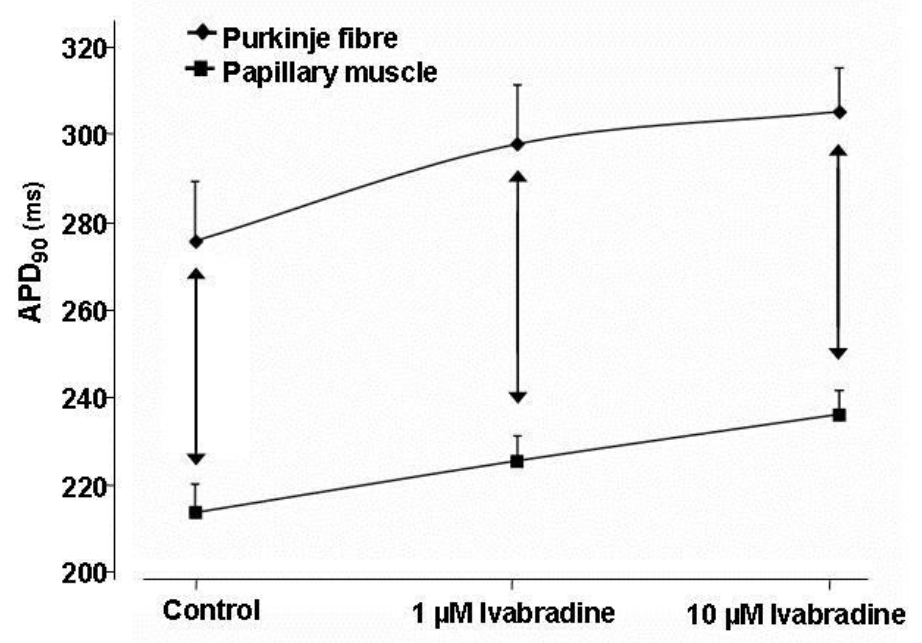

Fig. 17: Effect of ivabradine on dispersion of repolarization between dog Purkinje fibre and papillary muscle at basic cycle length of $1000 \mathrm{~ms}$. Results are mean \pm S.E.M. $n=10$ for Purkinje fibre and $n=8$ for papillary muscle. 


\section{DISCUSSION}

\subsection{Major findings}

In this thesis several effects of novel antianginal drugs on transmembrane action potentials are summarized. The effects of ranolazine and ivabradine were mainly investigated in dog, a species resembling human in heart size, spontaneous frequency and repolarization. The results led us to the conclusion that ranolazine and ivabradine at relatively high concentrations in dog and human cardiac preparations produce a concentration- and frequency-dependent depression of $\mathrm{V}_{\max }$ and able to prolong action potential duration i.e. exerts Class I and III antiarrhythmic actions. Ranolazine produces depression of $\mathrm{V}_{\max }$ with rather fast onset and offset kinetics, i.e. exerts Class $\mathrm{I} / \mathrm{B}$ antiarrhythmic action (similar to that of mexiletine) not only in normal and remodelled atria, but also in the ventricle. Other important finding is that due to its multiple ion channel blocking property, ranolazine alters the repolarization in a complex manner in remodelled atria. Ivabradine (at high concentrations) can be considered as a $\mathrm{Na}^{+}$channel blocker antiarrhythmic drug with slow kinetic onset and recovery i.e. exerts Class I/C antiarrhythmic action (similar to that of flecainide or propafenone). Ranolazine and ivabradine are devoid from the effect to increase the dispersion of repolarization between Purkinje fibres and the subendocardial muscle layers.

\subsection{Class I antiarrhythmic action}

The dose- and frequency dependent $\mathrm{V}_{\max }$ block (induced by ranolazine and ivabradine) could be attributed to the inhibition of the fast/peak $\mathrm{Na}^{+}$current. $\mathrm{V}_{\max }$ measurements are indicative for $\mathrm{I}_{\mathrm{Na}}$ function, but they cannot be used for quantitative estimation of sodium channel availability, since it could be underestimated [89]. It was demonstrated that $\mathrm{V}_{\max }$ could be regarded as a nonlinear indicator of the fast inward sodium current [90].

\subsection{1. $V_{\max }$ block in the ventricle}

The $\mathrm{V}_{\max }$ block of ranolazine was similar in frequency-dependent characteristic than that of class I/B antiarrhythmic drugs (e.g. mexiletine). In previous studies the drug was reported to produce atrial-predominant sodium channel block and postrepolarization refractoriness which was postulated in the mechanism of suppressing atrial fibrillation [29, 
31, 32, 36, 38]. The investigators did not apply properly wide range of stimulation frequencies $(\mathrm{BCL}=300-5000 \mathrm{~ms})$ in the presence of ranolazine at therapeutically meaningful concentration using the conventional microelectrode technique. Therefore the effect of ranolazine on peak $\mathrm{I}_{\mathrm{Na}}$ and conduction in the ventricle might have been underestimated and neglected. In a previous study the investigators found that ranolazine blocked peak $\mathrm{I}_{\mathrm{Na}}$ with high $\mathrm{IC}_{50}$ values (at 1,2 and $5 \mathrm{~Hz}$ were 260,157 and $154 \mu \mathrm{M}$, respectively) in HEK293 cells using whole-cell patch-clamp technique at room temperature [50] which is about one order of magnitude higher than our results based on $\mathrm{V}_{\max }$ measurements and should be extrapolated with caution to intact heart including humans. Fredj et al. [52] found preferential ranolazine block of sustained vs peak $\mathrm{Na}^{+}$ channel current for LQT-3 mutant channels $\left(\mathrm{IC}_{50}=15\right.$ vs $\left.135 \mu \mathrm{M}\right)$ also in HEK293 cells using patch-clamp technique at room temperature which ratio in our experiments - in 'healthy' cardiac preparations at $37^{\circ} \mathrm{C}$ - is almost $1: 1$. The effects of ranolazine on onset and offset kinetics of $\mathrm{V}_{\max }$ indicate that ranolazine kinetically resembles fast/intermediate (Class I/B) antiarrhythmic agents. Similar results were described by others earlier at high concentration $[29,31]$ using different protocol to determine unbinding kinetics.

The effects of ivabradine on recovery of $\mathrm{V}_{\max }$ observed in dog ventricular muscle indicate that ivabradine resembles kinetically slow antiarrhythmic agents. Frequencydependent $\mathrm{V}_{\max }$ block has been demonstrated previously only in small animals at high concentration $(50 \mu \mathrm{M})$ of ivabradine [91]. The possible decrease of $\mathrm{I}_{\mathrm{Na}}$ by ivabradine may contribute to the inhibition of the pacemaker function.

The sodium current determines greatly the velocity of impulse propagation through the His-Purkinje system, working atrial and ventricular cardiac tissue. Since ranolazine and ivabradine produced significant depression of $\mathrm{V}_{\max }$ at fast stimulation frequencies, it can therefore be expected that the drugs may suppress the impulse conduction at fast heart rate i.e. during tachycardia or that extrasystoles with short coupling interval during cardiac arrhythmias.

\subsection{2. $V_{\max }$ block in atria vs. ventricle}

The less negative resting potential, the greater density of sodium channels and the more negative half-inactivation voltage in atrial myocytes could make the sodium channel block more vigorous $[29,31]$. We investigated the possible difference in $\mathrm{V}_{\max }$ block between atria and ventricle in the example of ranolazine, since this drug was reported to produce atrial-predominant use dependent block of sodium channels and postrepolarization 
refractoriness which was postulated in the mechanism of suppressing atrial fibrillation [29, $31,32]$. Similarly to that described by others earlier $[29,31]$ the decrease in $V_{\max }$ was more pronounced in the atria than in the ventricle. However, in our experiments the $\mathrm{V}_{\max }$ block and consequently the CT were also substantial (at fast stimulation frequencies) in ventricular preparations.

\subsection{3. $V_{\max }$ block in normal vs. remodelled atria}

Since it has been suggested that ranolazine application could be effective in atrial fibrillation, we investigated the possible difference in $\mathrm{V}_{\max }$ block between normal and remodelled atria in the example of ranolazine. Remodelled atrial preparations were obtained from tachypacing induced remodelled dog herats (used as an established model for mimicing the pathological tissue in atrial fibrillation). The frequency dependent $\mathrm{V}_{\max }$ block was less pronounced in remodelled than in normal atria. This is in accordance with a previous study in which reduced peak $\mathrm{I}_{\mathrm{Na}}$ density was detected in $\mathrm{AF}$ [92]. The less pronounced effect on $\mathrm{V}_{\max }$ by ranolazine in remodelled atrial tissue can be explained by shorter repolarization and, as a consequence, longer diastolic intervals allowing more recovery at each cycle. In AF the use-dependent $\mathrm{Na}^{+}$channel block by ranolazine most likely enhances postrepolarization refractoriness in addition to the repolarization lengthening in the remodelled atria. Despite the prolongation in the $\mathrm{APD}_{90}$, ranolazine decreased the $\mathrm{APD}_{50}$ value in remodelled atria, which may reflect inhibitory effect on late $\mathrm{I}_{\mathrm{Na}}$. The latter current was recently reported to be upregulated in isolated human atrial myocytes obtained from AF patients in experiments with patch-clamp technique [92].

\subsection{4. $V_{\max }$ block in case of elevated extracellular potassium concentration}

Block of sodium current has been demonstrated to be more pronounced when the resting membrane potential is partly depolarized [72] e.g. in ischemic tissues. We investigated this phenomenon in the example of ranolazine induced $\mathrm{V}_{\max }$ block in case of normal $(4 \mathrm{mM})$ and elevated $(6 \mathrm{mM})$ extracellular potassium concentration. Depression of $\mathrm{V}_{\max }$ and conduction were more pronounced in case of elevated potassium concentration, e.g. when the resting membrane potential is partly depolarized, even as in the presence of an ischaemic cardiac substrate.

It can therefore be expected that the drugs may suppress the impulse conduction at fast heart rate i.e. during tachycardia or that extrasystoles with short coupling interval during cardiac arrhythmias in patients with angina pectoris. 


\subsection{Class III antiarrhythmic action}

The repolarization lengthening effect of ranolazine and ivabradine could be best explained by the drug evoked $\mathrm{I}_{\mathrm{Kr}}$ block. In various cardiac preparations, the effect of ranolazine and ivabradine on APD depends on the different density of various ion channels (late $\mathrm{I}_{\mathrm{Na}}$, late $\mathrm{I}_{\mathrm{Ca}}, \mathrm{I}_{\mathrm{Kr}}, \mathrm{I}_{\mathrm{Ks}}$ ) and the extent of blocking effects of the compounds on these channels. The antiarrhythmic efficacy of most pure class III drugs is compromised by their inherent property to induce excessive lengthening of the action potential (reverse frequency dependence) and their inability to prolong the action potential when most needed, namely during tachycardia [94]. Overall, an ideal antiarrhythmic agent does not exist, and drug selection should be highly individualized [95-97]. In case of ranolazine and ivabradine the additional sodium channel block would limit action potential prolongation at slow rate due to the $\mathrm{I}_{\mathrm{Kr}}$ inhibition.

Ranolazine has been shown to cause a slight prolongation of the QT interval on the ECG [24, 47, 98]. In dog midmyocardial preparations ranolazine $(20 \mu \mathrm{M})$ produced prolongation of repolarization in accordance with the previous (clinical) observation. Ivabradin exerted significant prolongation of repolarization in human preparations only at higher concentration $(10 \mu \mathrm{M})$.

\subsubsection{Attenuated repolarization reserve}

Remodelling [99], pharmacological modulation [2-4] or genetic channelophathies [100] of certain potassium channels, which normally contribute to repolarization, can attenuate the capability of the heart to repolarize. In these situations inhibition of other potassium channels may lead to unexpectedly augmented APD prolongation, resulting in proarrhythmic reactions. In previous studies the investigators found that ivabradine at 3 and $10 \mu \mathrm{M}$ prolongs repolarization in guinea-pig papillary muscles [91, 101]. Our results support the action potential lengthening effect of ivabardine also in dog and human cardiac preparations especially in case of attenuated repolarization reserve.

\subsection{Class V antiarrhythmic action}

Ivabradine is originally a class $\mathrm{V}$ antiarrhytmic agent with antianginal property, since the drug exerts well-known $I_{f}$ blocking effect. Ivabradine induces (a marked exponential use-dependent) blockade of the hyperpolarization activated $\mathrm{I}_{\mathrm{f}}$ current with relatively high $(2.8 \mu \mathrm{M}) \mathrm{IC}_{50}$ in rabbit sinus node cells [102]. Ivabradine concentration-dependently 
decreased the steepness of spontaneous diastolic depolarization and slowed spontaneous rate of firing of the Purkinje fibres which effect could be best explained by the drug evoked If block. This ability on Purkinje fibres might be considered as an antiarrhythmic property and might suppress the initiation of arrhythmias. Ranolazine does not exert class $\mathrm{V}$ antiarrhythmic action.

\subsection{Dispersion of ventricular repolarization}

In Purkinje fibres, where the late $\mathrm{I}_{\mathrm{Na}}$ is robust, ranolazine and ivabradine produced shortening of $\mathrm{APD}_{50}$. This impact on the plateau slope might be related to the inhibitory effect of the drugs on the persistent, 'window' (late $\mathrm{I}_{\mathrm{Na}}$ ) current. Block of this $\mathrm{Na}^{+}$current might also have an additional therapeutic value [103] and would also limit action potential prolongation at slow rate due to the $\mathrm{I}_{\mathrm{Kr}}$ inhibition of the drugs at higher concentration. Owing to this 'dirty' (mixed) characteristic, ranolazine and ivabradine are devoid from the effect to increase the dispersion of repolarization between Purkinje fibres and the subendocardial muscle layers, oppositely in case of 'pure' class III drugs. This ability can be considered as an advantageous property [104]. Excessive shortening of the Purkinje fibre APD may increase the risk of reentry [105], but in the case of ranolazine and ivabradine the mentioned $\mathrm{I}_{\mathrm{Kr}}$ blocking effect and the postrepolarization refractoriness (due to the sodium channel blockade) attenuate this potential risk factor also.

\subsection{Human cardiac tissue}

To our knowledge our results were the first in which the effects of ranolazine and ivabradine were investigated in human ventricular muscle preparations with conventional microelectrode technique. We observed depression of the $\mathrm{V}_{\max }$ to similar extent as in dog papillary muscles. Ivabradine at $10 \mu \mathrm{M}$ exerted significant effect on action potential duration also in human ventricular preparations. Our results suggest that late $\mathrm{I}_{\mathrm{Na}}$ has less contribution to repolarization in dog than in human ventricular preparations. In case of ranolazine $\mathrm{APD}_{50}$ values were shortened in human but not in dog ventricular muscle (Table 3 and 4). In this context it should be noted that biphasic time dependent changes were observed (especially in human preparations) with ranolazine, i.e. the APD shortening effect always preceded the drug evoked tendency to repolarization lengthening. The initial shortening of APD was much greater in human than in dog, which may also indicate, that late $\mathrm{I}_{\mathrm{Na}}$ has less contribution to repolarization in dog. 


\subsection{Therapeutically relevant concentrations of the drugs}

The therapeutically relevant concentration of ranolazine and ivabradine should be interpreted with great caution. For example in previous studies the authors interpreted 2-10 $\mu \mathrm{M}$ ranolazine as therapeutically relevant concentration, but they did not provide a cross reference to a factual effective plasma level [29, 30, 50, 106, 107]. Authors report steady state through levels at a therapeutic dose in man to be $464 \mathrm{ng} / \mathrm{ml}$ [108]. This equates to a plasma concentration of 1 micromolar. Thus the doses used in our study may 5- to 20-fold higher than therapeutic concentration according to this article.

In case of ivabradine though therapeutic plasma concentrations are about 0.04-0.07 $\mu \mathrm{M}$, the drug has been tested at higher $(0.17 \mu \mathrm{M})$ concentration in healthy volunteers [109]. Other investigators [110] interpreted $3 \mu \mathrm{M}$ ivabradine as „clinically relevant" concentration. Therefore the $(0.1-1-10 \mu \mathrm{M})$ concentrations applied in our experiments may be relevant, since the tissue concentration can be expected to be higher than that of the plasma, in accordance with the high volume of distribution (close to $100 \mathrm{~L}$ ) value of the drug. In this context, the relatively low therapeutic plasma concentration might be the result of possibly meaningful tissue appearance of ivabradine. We did not find significant effect of $0.1 \mu \mathrm{M}$ ivabradine on $\mathrm{V}_{\max }$ and APD measurements (data not shown).

\subsection{Clinical implications}

It has to be emphasized that the drugs so far have proved to be safe and free from any proarrhythmic events in clinical trials [22-24, 111, 112]. The sodium channel blocking ability on Purkinje fibres might be considered as an antiarrhythmic property and might suppress the initiation of an extrasystole, limit any repolarization lengthening and most importantly, it could decrease dispersion of repolarization. Since ranolazine and ivabradine produced significant depression of $\mathrm{V}_{\max }$ at fast stimulation frequencies, it can therefore be expected that the drugs may suppress the impulse conduction at fast heart rate i.e. during tachycardia or that extrasystoles with short coupling interval during cardiac arrhythmias. However the possible contribution of this effect to the clinical benefit of the drug is still unclear. The properties of ranolazine resemble that of chronically administered amiodarone and may represent antiarrhythmic property. Amiodarone has minimal proarrhythmic risk, but has numerous noncardiac toxicities that require frequent monitoring [113, 114]. Clinical findings support the suggestion that ranolazine might be efficacious not only in supraventricular but also in ventricular arrhythmias [51]. Although proarrhythmic side 
effects do not seem to be a major concern during ranolazine and ivabradine application, they can not be completely ruled out in some pathological conditions, e.g. in case of drug accumulation or intoxication, or in case of attenuated repolarization reserve like in heart failure, diabetes or in long QT syndromes. Therefore, further studies with ranolazine and ivabradine are needed to determine its safety and efficacy in future clinical use. 


\section{CONCLUSIONS}

Based on the cellular cardiac electrophysiological properties of ranolazine and ivabradine it can be concluded that these antianginal drugs also exert Class I and III antiarrhythmic properties (at higher concentrations) which can be advantageous in the treatment of patients with ischemic heart disease, heart failure [115] liable to disturbances of cardiac rhythm. Ranolazine decreases (and ivabradine does not increase) the dispersion of ventricular repolarization (the difference in $\mathrm{APD}_{90}$ values between Purkinje fibres and papillary muscles), which can contribute to the antiarrhythmic property of the drugs. Ranolazine exerts amiodaron-like antiarrhythmic properties, without serious side-effects. Ivabradine is beneficial in patients with angina pectoris equally to beta receptor blockers without producing any negative inotropic or vasoconstrictor effect. Based on the recent clinical trials and experiments, widening the indication of the drugs is expected (heart failure and atrial fibrillation for ranolazine; myocardial infarction and heart failure for ivabradine).

These 'dirty' drugs combine several modes of antiarrhythmic actions which might be the key to find a drug that has powerful antiarrhythmic potential with lack of proarrhythmic side effects. 


\section{REFERENCES}

[1] Roden DM. Taking the "idio" out of "idiosyncratic": predicting torsades de pointes. Pacing Clin Electrophysiol. 1998; 21(5), 1029-34.

[2] Varro A., Balati B., Iost N., Takacs J., Virag L., Lathrop DA., Csaba L., Tálosi L., Papp JG. The role of the delayed rectifier component IKs in dog ventricular muscle and Purkinje fibre repolarization. J Physiol. 2000; 523 Pt 1, 67-81.

[3] Biliczki P., Virag L., Iost N., Papp JG., Varro A. Interaction of different potassium channels in cardiac repolarization in dog ventricular preparations: role of repolarization reserve. Br J Pharmacol. 2002; 137(3), 361-8.

[4] Jost N., Virag L., Bitay M., Takacs J., Lengyel C., Biliczki P., Nagy Z., Bogáts G., Lathrop DA., Papp JG., Varro A. Restricting excessive cardiac action potential and QT prolongation: a vital role for IKs in human ventricular muscle. Circulation. 2005; 112(10), 1392-9.

[5] Banyasz T., Magyar J., Szentandrassy N., Horvath B., Birinyi P., Szentmiklosi J., Nanasi PP. Action potential clamp fingerprints of $\mathrm{K}+$ currents in canine cardiomyocytes: their role in ventricular repolarization. Acta Physiol (Oxf). 2007; 190(3), 189-98.

[6] DiFrancesco D. The pacemaker current (If) plays an important role in regulating SA node pacemaker activity. Cardiovasc Res. 1995; 30, 307-308.

[7] Singh B.N., Vaughan Williams E.M. A third class of anti-arrhythmic action. Effect on atrial and ventricular intracellular potentials, and other pharmacological actions on cardiac muscle, of MJ 1999 and AH 3474. Br J Pharmacol. 1970; 39, 675-687.

[8] Singh B.N. A fourth class of anti-dysrhythmic action? Effect of verapamil on ouabain toxicity, on atrial and ventricular intracellular potentials, and on other features of cardiac function. Cardiovasc Res. 1972; 6, 109-119.

[9] Nattel S., Singh B.N. Evolution, mechanisms, and classification of antiarrhythmic drugs: focus on class III actions. Am J Cardiol. 1999; 84, 11R-19R.

[10] The CAST Investigators. Preliminary report: effect of encainide and flecainide on mortality in randomized trial arrhythmia suppression after myocardial infarction. N Engl J Med. 1989; 321, 406-412.

[11] Pinney S.P., Koller B.S., Frany M.R., Woosley R.L. Terfenadine increases the QT interval in isolated guinea pig heart. J Cardiovasc Pharmacol. 1995; 25, 30-40.

[12] Gintant G.A., Limberis J.T., McDermott J.S., Wegner C.D., Cox B.F. The canine Purkinje fiber: an in vitro model system for acquired long QT syndrome and drug-induced arrhythmogenesis. J Cardiovasc Pharmacol. 2001; 37, 607-618.

[13] Antzelevitch C., Sun Z.Q., Zhang Z.Q., Yan G.X. Cellular and ionic mechanisms underlying erythromycin-induced long QT intervals and torsade de pointes. J Am Coll Cardiol. 1996; 28, 1836-1848.

[14] Drici M.D., Barhanin J. Cardiac $\mathrm{K}^{+}$channels and drug-acquired long QT syndrome. Therapie. 2000; 55, 185-193.

[15] Rampe D., Murawsky M.K. Blockade of the human cardiac K+ channel Kv1.5 by the antibiotic erythromycin. Naunyn-Schmiedebergs Archiv Pharmacol. 1997; 355, 743750 .

[16] Waldo A.L., Camm A.J., deRuyter H., Friedman P.L., MacNeil D.J., Pauls J.F., Pitt B., Pratt C.M., Schwartz P.J., Veltri E.P. Effect of d-sotalol on mortality in patients with left ventricular dysfunction after recent and remote myocardial infarction. The SWORD Investigators. Survival with oral d-sotalol. Lancet. 1996; 348, 7-12.

[17] Brendorp B., Elming H., Jun L., Kober L., Malik M., Jensen G.B., Torp-Pedersen C. The DIAMOND Study Group. QTc interval as a guide to select those patients with 
congestive heart failure and reduced left ventricular systolic function who will benefit from antiarrhythmic treatment with dofetilide. Circulation. 2001; 103, 1422-1427.

[18] Hondeghem L.M., Snyders D.J. Class III antiarrhythmic agents have a lot of potential but a long way to go. Reduced effectiveness and dangers of reverse use dependence. Circulation. 1990; 81, 686-690.

[19] Hohnloser S.H., Woosley R.L. Sotalol. New Engl J Med. 1994; 331, 31-38.

[20] Van de Werf F., Bax J., Betriu A., Blomstrom-Lundqvist C., Crea F., Falk V., Filippatos G., Fox K., Huber K., Kastrati A., Rosengren A., Steg PG., Tubaro M., Verheugt F., Weidinger F., Weis M. Management of acute myocardial infarction in patients presenting with persistent STsegment elevation. Eur Heart J. 2008; 29, 2909-2945.

[21] Heusch G., Schulz R. The role of heart rate and the benefits of heart rate reduction in acute myocardial ischaemia. Eur Heart J. Suppl. 2007; 9(F), 8-14.

[22] Pepine C.J., Wolff A.A. A controlled trial with a novel anti-ischemic agent, ranolazine, in chronic stable angina pectoris that is responsive to conventional antianginal agents. Ranolazine Study Group. Am J Cardiol. 1999; 84, 46-50.

[23] Louis A.A., Manousos I.R., Coletta A.P., Clark A.L., Cleland J.G. Clinical trials update: The Heart Protection Study, IONA, CARISA, ENRICHD, ACUTE, ALIVE, MADIT II and REMATCH. Impact Of Nicorandil on Angina. Combination Assessment of Ranolazine In Stable Angina. ENhancing Recovery In Coronary Heart Disease patients. Assessment of Cardioversion Using Transoesophageal Echocardiography. AzimiLide postInfarct surVival Evaluation. Randomised Evaluation of Mechanical Assistance for Treatment of Chronic Heart failure. Eur J Heart Fail. 2002; 4, 111-116.

[24] Chaitman B.R., Pepine C.J., Parker J.O., Skopal J., Chumakova G., Kuch J., Wang W., Skettino S.L., Wolff A.A. Effects of ranolazine with atenolol, amlodipine, or diltiazem on exercise tolerance and angina frequency in patients with severe chronic angina: a randomized controlled trial. Jama. 2004; 291, 309-316.

[25] Sendón J.L., Lee S., Cheng M.L., Ben-Yehuda O., CARISA study investigators. Effects of ranolazine on exercise tolerance and angina frequency in patients with severe chronic angina receiving maximally-tolerated background therapy: analysis from the Combination Assessment of Ranolazine In Stable Angina (CARISA) randomized trial. Eur J Prev Cardiol. 2012; 19(5), 952-9.

[26] Antzelevitch C., Belardinelli L., Zygmunt A.C., Burashnikov A., Di Diego J.M., Fish J.M., Cordeiro J.M., Thomas G. Electrophysiological effects of ranolazine, a novel antianginal agent with antiarrhythmic properties. Circulation. 2004; 110, 904-910.

[27] Antzelevitch C., Belardinelli L., Wu L., Fraser H., Zygmunt A.C., Burashnikov A., Di Diego J.M., Fish J.M., Cordeiro J.M., Goodrow R.J., Jr., Scornik F., Perez G. Electrophysiologic properties and antiarrhythmic actions of a novel antianginal agent. J Cardiovasc Pharmacol Ther. 2004; 9 (Suppl 1), S65-83

[28] Wu L., Shryock J.C., Song Y., Li Y., Antzelevitch C., Belardinelli L. Antiarrhythmic effects of ranolazine in a guinea pig in vitro model of long-QT syndrome. $\mathrm{J}$ Pharmacol Exp Ther. 2004; 310, 599-605.

[29] Burashnikov A., Di Diego J.M., Zygmunt A.C., Belardinelli L., Antzelevitch C. Atrium-selective sodium channel block as a strategy for suppression of atrial fibrillation: differences in sodium channel inactivation between atria and ventricles and the role of ranolazine. Circulation. 2007; 116, 1449-1457.

[30] Sicouri S., Glass A., Belardinelli L., Antzelevitch C. Antiarrhythmic effects of ranolazine in canine pulmonary vein sleeve preparations. Heart Rhythm. 2008; 5, 10191026.

[31] Antzelevitch C., Burashnikov A. Atrial-selective sodium channel block as a novel strategy for the management of atrial fibrillation. J Electrocardiol. 2009; 42, 543-548. 
[32] Kumar K., Nearing B.D., Carvas M., Nascimento B.C., Acar M., Belardinelli L., Verrier R.L. Ranolazine exerts potent effects on atrial electrical properties and abbreviates atrial fibrillation duration in the intact porcine heart. J Cardiovasc Electrophysiol. 2009; 20, 796-802.

[33] Tagarakis G.I., Aidonidis I., Daskalopoulou S.S., Simopoulos V., Liouras V., Daskalopoulos M.E., Parisis C., Papageorgiou K., Skoularingis I., Triposkiadis F., Molyvdas P.A., Tsilimingas N.B. Effect of Ranolazine in Preventing Postoperative Atrial Fibrillation in Patients Undergoing Coronary Revascularization Surgery. Curr Vasc Pharmacol. 2012; 10, 000-000.

[34] Fragakis N., Koskinas K.C., Katritsis D.G., Pagourelias E.D., Zografos T., Geleris P. Comparison of effectiveness of ranolazine plus amiodarone versus amiodarone alone for conversion of recent-onset atrial fibrillation. Am J Cardiol. 2012; 110(5), 673-7.

[35] Burashnikov A., Antzelevitch C. Ranolazine versus amiodarone for prevention of postoperative atrial fibrillation. Future Cardiol. 2011; 7(6), 733-7.

[36] Burashnikov A., Belardinelli L., Antzelevitch C. Atrial-selective sodium channel block strategy to suppress atrial fibrillation: ranolazine versus propafenone. J Pharmacol Exp Ther. 2012; 340(1), 161-8.

[37] Frommeyer G., Schmidt M., Clauß C., Kaese S., Stypmann J., Pott C., Eckardt L., Milberg P. Further insights into the underlying electrophysiological mechanisms for reduction of atrial fibrillation by ranolazine in an experimental model of chronic heart failure. Eur J Heart Fail. 2012; 14, 1322-1331.

[38] Aidonidis I., Doulas K., Hatziefthimiou A., Tagarakis G., Simopoulos V., Rizos I., Tsilimingas N., Molyvdas P.A. Ranolazine-Induced Postrepolarization Refractoriness Suppresses Induction of Atrial Flutter and Fibrillation in Anesthetized Rabbits. J Cardiovasc Pharmacol Ther. 2012; 18(1), 94-101.

[39] Verrier R.L., Pagotto V.P., Kanas A.F., Sobrado M.F., Nearing B.D., Zeng D., Belardinelli L. Low doses of ranolazine and dronedarone in combination exert potent protection against atrial fibrillation and vulnerability to ventricular arrhythmias during acute myocardial ischemia. Heart Rhythm. 2012; 10(1), 121-127.

[40] Sicouri S., Blazek J., Belardinelli L., Antzelevitch C. Electrophysiological characteristics of canine superior vena cava sleeve preparations: effect of ranolazine. Circ Arrhythm Electrophysiol. 2012; 5, 371-379.

[41] Sicouri S., Pourrier M., Gibson J.K., Lynch J.J., Antzelevitch C. Comparison of electrophysiological and antiarrhythmic effects of vernakalant, ranolazine, and sotalol in canine pulmonary vein sleeve preparations. Heart Rhythm. 2012; 9(3), 422-9.

[42] Frommeyer G., Kaiser D., Uphaus T., Kaese S., Osada N., Rajamani S., Belardinelli L., Breithardt G., Eckardt L., Milberg P. Effect of ranolazine on ventricular repolarization in class III antiarrhythmic drug-treated rabbits. Heart Rhythm. 2012; 9(12), 2051-8.

[43] Belardinelli L., Liu G., Smith-Maxwell C., Wang W.Q., El-Bizri N., Hirakawa R., Karpinski S., Kornyeyev D., Li C.H., Hu L., Li X.J., Crumb W., Wu L., Koltun D., Zablocki J., Yao L., Dhalla A.K., Rajamani S., Shryock J. A Novel, Potent, and Selective Inhibitor of Cardiac Late Sodium Current Suppresses Experimental Arrhythmias. J Pharmacol Exp Ther. 2012; 344(1), 23-32.

[44] Radwański P.B., Greer-Short A., Poelzing S. Inhibition of $\mathrm{Na}(+)$ channels ameliorates arrhythmias in a drug-induced model of Andersen-Tawil syndrome. Heart Rhythm. 2012; 10(2), 255-63.

[45] Sossalla S., Maier L.S. Role of ranolazine in angina, heart failure, arrhythmias, and diabetes. Pharmacol Ther. 2012; 133, 311-323. 
[46] Allen T.J., Chapman R.A. Effects of ranolazine on L-type calcium channel currents in guinea-pig single ventricular myocytes. Br J Pharmacol. 1996; 118, 249-254.

[47] Schram G., Zhang L., Derakhchan K., Ehrlich J.R., Belardinelli L., Nattel S. Ranolazine: ion-channel-blocking actions and in vivo electrophysiological effects. Br $\mathbf{J}$ Pharmacol. 2004; 142, 1300-1308.

[48] Song Y., Shryock J.C., Wu L., Belardinelli L. Antagonism by ranolazine of the proarrhythmic effects of increasing late INa in guinea pig ventricular myocytes. J Cardiovasc Pharmacol. 2004; 44, 192-199.

[49] Rajamani S., Shryock J.C., Belardinelli L. Block of tetrodotoxin-sensitive, $\mathrm{Na}(\mathrm{V}) 1.7$ and tetrodotoxin-resistant, $\mathrm{Na}(\mathrm{V}) 1.8, \mathrm{Na}+$ channels by ranolazine. Channels (Austin). 2008; 2, 449-460.

[50] Rajamani S., El-Bizri N., Shryock J.C., Makielski J.C., Belardinelli L. Usedependent block of cardiac late $\mathrm{Na}(+)$ current by ranolazine. Heart Rhythm. 2009; 6, 16251631.

[51] Scirica B.M., Morrow D.A., Hod H., Murphy S.A., Belardinelli L., Hedgepeth C.M., Molhoek P., Verheugt F.W., Gersh B.J., McCabe C.H., Braunwald E. Effect of ranolazine, an antianginal agent with novel electrophysiological properties, on the incidence of arrhythmias in patients with non ST-segment elevation acute coronary syndrome: results from the Metabolic Efficiency With Ranolazine for Less Ischemia in Non ST-Elevation Acute Coronary Syndrome Thrombolysis in Myocardial Infarction 36 (MERLIN-TIMI 36) randomized controlled trial. Circulation. 2007; 116, 1647-1652.

[52] Fredj S., Sampson K.J., Liu H., Kass R.S. Molecular basis of ranolazine block of LQT-3 mutant sodium channels: evidence for site of action. Br J Pharmacol. 2006; 148, $16-24$.

[53] Wu L., Shryock J.C., Song Y., Belardinelli L. An increase in late sodium current potentiates the proarrhythmic activities of low-risk QT-prolonging drugs in female rabbit hearts. J Pharmacol Exp Ther. 2006; 316, 718-726.

[54] Sicouri S., Timothy K.W., Zygmunt A.C., Glass A., Goodrow R.J., Belardinelli L., Antzelevitch C. Cellular basis for the electrocardiographic and arrhythmic manifestations of Timothy syndrome: effects of ranolazine. Heart Rhythm. 2007; 4, 638-647.

[55] Moss A.J., Zareba W., Schwarz K.Q., Rosero S., McNitt S., Robinson J.L. Ranolazine shortens repolarization in patients with sustained inward sodium current due to type-3 long-QT syndrome. J Cardiovasc Electrophysiol. 2008; 19, 1289-1293.

[56] Wu J., Cheng L., Lammers W.J., Wu L., Wang X., Shryock J.C., Belardinelli L., Lei M. Sinus node dysfunction in ATX-II-induced in-vitro murine model of long QT3 syndrome and rescue effect of ranolazine. Prog Biophys Mol Biol. 2008; 98, 198-207.

[57] Antoons G., Oros A., Beekman J.D., Engelen M.A., Houtman M.J., Belardinelli L., Stengl M., Vos M.A. Late na(+) current inhibition by ranolazine reduces torsades de pointes in the chronic atrioventricular block dog model. J Am Coll Cardiol. 2010; 55, 801809.

[58] Vilaine J.P., Thollon C., Villeneuve N., Peglion J.L. Procoralan, a new selective If current inhibitor. Eur Heart J. 2003; Supplements 5, 26-35.

[59] Joannides R., Moore N., Iacob M., Compagnon P., Lerebours G., Menard J.F., Thuillez C. Comparative effects of ivabradine, a selective heart rate-lowering agent, and propranolol on systemic and cardiac haemodynamics at rest and during exercise. Br J Clin Pharmacol. 2005; 61, 127-137.

[60] Fox K., Ford I., Steg P.G., Tendera M., Ferrari R. Ivabradine for patients with stable coronary artery disease and left-ventricular systolic dysfunction (BEAUTIFUL): a randomised, double-blind, placebo-controlled trial. Lancet. 2008; 372, 807-816.

[61] Savelieva I., Camm AJ. Novel If current inhibitor ivabradine: safety considerations. 
Adv Cardiol. 2006; 43, 79-96.

[62] Borer JS., Fox K., Jaillon P., Lerebours G., Ivabradine Investigators. Antianginal and antiischemic effects of ivabradine, an If inhibitor, in stable angina. Circulation. 2003; $107,817-823$.

[63] Tardif JC., Ford I., Tendera M., Bourassa MG., Fox K., INITIATIVE Investigators. Efficacy of ivabradine, a new selective I(f) inhibitor, compared with atenolol in patients with chronic stable angina. Eur Heart J. 2005; 26(23), 2529-2536.

[64] Swedberg K., Komajda M., Böhm M., Borer JS., Ford I., Dubost-Brama A., Lerebours G., Tavazzi L. SHIFT Investigators. Ivabradine and outcomes in chronic heart failure (SHIFT): a randomised placebo-controlled study. Lancet. 2010; 376(9744), 875885.

[65] Heusch G., Skyschally A., Gres P., van Caster P., Schilawa D., Schulz R. Improvement of regional myocardial blood flow and function and reduction of infarct size with ivabradine: protection beyond heart rate reduction. Eur Heart J. 2008; 29, 2265-2275. [66] Vizzardi E., Bonadei I., D'Aloia A., Del Magro F., Piovanelli B., Bontempi L., Curnis A., Dei Cas L. The importance of reducing heart rate in cardiovascular diseases: effects of Ivabradine. Minerva Med. 2011; 102(5), 373-9.

[67] Ferrari R., Ceconi C. Selective and specific I(f) inhibition with ivabradine: new perspectives for the treatment of cardiovascular disease. Expert Rev Cardiovasc Ther. 2011; 9(8), 959-73.

[68] Tardif J.C., Ponikowski P., Kahan T., on behalf of the ASSOCIATE investigators. Effects of ivabradine in patients with stable angina receiving beta-blockers according to baseline heart rate: an analysis of the ASSOCIATE study. Int J Cardiol. 2012.

[69] Riccioni G., Prencipe G., Benvenuto A., Masciocco L., Ventra S., Rizzo U., Russi C., Speziale G. Ivabradine Improves All Aspects of Quality of Life Assessed with the 36Item Short Form Health Survey in Subjects with Chronic Ischemic Heart Disease Compared with Beta-Blockers. Pharmacology. 2012; 91(1-2), 35-38.

[70] Werdan K., Ebelt H., Nuding S., Höpfner F., Hack G., Müller-Werdan U. Ivabradine in combination with beta-blocker improves symptoms and quality of life in patients with stable angina pectoris: results from the ADDITIONS study. Clin Res Cardiol. 2012; 101(5), 365-73.

[71] Amosova E., Andrejev E., Zaderey I., Rudenko U., Ceconi C., Ferrari R. Efficacy of ivabradine in combination with Beta-blocker versus uptitration of Beta-blocker in patients with stable angina. Cardiovasc Drugs Ther. 2011; 25(6), 531-7.

[72] Danchin N., Marzilli M., Parkhomenko A., Ribeiro J.P. Efficacy comparison of trimetazidine with therapeutic alternatives in stable angina pectoris: a network metaanalysis. Cardiology. 2011; 120(2), 59-72.

[73] Guglin M. Heart rate reduction in heart failure: ivabradine or beta blockers? Heart Fail Rev. 2012.

[74] Kapoor J.R., Heidenreich P.A. Role of heart rate as a marker and mediator of poor outcome for patients with heart failure. Curr Heart Fail Rep. 2012; 9(2), 133-8.

[75] Haddad H., Mielniczuk L., Davies R.A. Recent advances in the management of chronic heart failure. Curr Opin Cardiol. 2012; 27(2), 161-8.

[76] Heusch G., Skyschally A., Schulz R. Cardioprotection by ivabradine through heart rate reduction and beyond. J Cardiovasc Pharmacol Ther. 2011; 16(3-4), 281-4.

[77] Canet E., Lerebours G., Vilaine J.P. Innovation in coronary artery disease and heart failure: clinical benefits of pure heart rate reduction with ivabradine. Ann N Y Acad Sci. 2011; 1222, 90-9.

[78] Perry C.M. Ivabradine: in adults with chronic heart failure with reduced left ventricular ejection fraction. Am J Cardiovasc Drugs. 2012; 12(6), 415-26. 
[79] Tan L.B., Schlosshan D., Hall A.S. Cardiac functional benefits of ivabradine therapy in patients with severe heart failure. Int J Cardiol. 2012.

[80] Borer J.S., Böhm M., Ford I., Komajda M., Tavazzi L., Sendon J.L., Alings M., Lopez-de-Sa E., Swedberg K., on behalf of the SHIFT Investigators. Effect of ivabradine on recurrent hospitalization for worsening heart failure in patients with chronic systolic heart failure: the SHIFT Study. Eur Heart J. 2012; 33(22), 2813-2820.

[81] Reil J.C., Hohl M., Reil G.H., Granzier H.L., Kratz M.T., Kazakov A., Fries P., Müller A., Lenski M., Custodis F., Gräber S., Fröhlig G., Steendijk P., Neuberger H.R., Böhm M. Heart rate reduction by If-inhibition improves vascular stiffness and left ventricular systolic and diastolic function in a mouse model of heart failure with preserved ejection fraction. Eur Heart J. 2012.

[82] Böhm M., Borer J., Ford I., Gonzalez-Juanatey J.R., Komajda M., Lopez-Sendon J., Reil J.C., Swedberg K., Tavazzi L. Heart rate at baseline influences the effect of ivabradine on cardiovascular outcomes in chronic heart failure: analysis from the SHIFT study. Clin Res Cardiol. 2012; 102(1), 11-22.

[83] Becher P.M., Lindner D., Miteva K., Savvatis K., Zietsch C., Schmack B., Van Linthout S., Westermann D., Schultheiss H.P., Tschöpe C. Role of heart rate reduction in the prevention of experimental heart failure: comparison between If-channel blockade and $\beta$-receptor blockade. Hypertension. 2012; 59(5), 949-57.

[84] Fang Y., Debunne M., Vercauteren M., Brakenhielm E., Richard V., Lallemand F., Henry J.P., Mulder P., Thuillez C. Heart rate reduction induced by the if current inhibitor ivabradine improves diastolic function and attenuates cardiac tissue hypoxia. J Cardiovasc Pharmacol. 2012; 59(3), 260-7.

[85] Ekman I., Chassany O., Komajda M., Böhm M., Borer J.S., Ford I., Tavazzi L., Swedberg K. Heart rate reduction with ivabradine and health related quality of life in patients with chronic heart failure: results from the SHIFT study. Eur Heart J. 2011; 32(19), 2395-404.

[86] Volterrani M., Cice G., Caminiti G., Vitale C., D'Isa S., Perrone Filardi P., Acquistapace F., Marazzi G., Fini M., Rosano G.M. Effect of Carvedilol, Ivabradine or their combination on exercise capacity in patients with Heart Failure (the CARVIVA HF trial). Int J Cardiol. 2011; 151(2), 218-24.

[87] Nattel S., Burstein B., Dobrev D. Atrial remodeling and atrial fibrillation: mechanisms and implications. Circ Arrhythm Electrophysiol. 2008; 1, 62-73.

[88] Hondeghem L.M., Katzung B.G. Antiarrhythmic agents: the modulated receptor mechanism of action of sodium and calcium channel-blocking drugs. Annu Rev Pharmacol Toxicol. 1984; 24, 387-423.

[89] Sheets M.F., Hanck D.A., Fozzard H.A. Nonlinear relation between Vmax and INa in canine cardiac Purkinje cells. Circ Res. 1988; 63, 386-398.

[90] Cohen C.J., Bean B.P., Tsien R.W. Maximal upstroke velocity as an index of available sodium conductance. Comparison of maximal upstroke velocity and voltage clamp measurements of sodium current in rabbit Purkinje fibers. Circ Res. 1984; 54, 636651.

[91] Pérez O., Gay P., Fanqueza L., Carrón R., Valenzuela C., Delpón E., Tamargo J. Effects of the two enantiomers, S-16257-2 and S-16260-2, of a new bradycardic agent on guinea-pig isolated cardiac preparations. Br J Pharmacol. 1995; 115, 787-794.

[92] Sossalla S., Kallmeyer B., Wagner S., Mazur M., Maurer U., Toischer K., Schmitto J.D., Seipelt R., Schondube F.A., Hasenfuss G., Belardinelli L., Maier L.S. Altered Na(+) currents in atrial fibrillation effects of ranolazine on arrhythmias and contractility in human atrial myocardium. J Am Coll Cardiol. 2010; 55, 2330-2342. 
[93] Pu J., Balser J.R., Boyden P.A. Lidocaine action on Na+ currents in ventricular myocytes from the epicardial border zone of the infarcted heart. Circ Res. 1998; 83, 431440.

[94] Jurkiewicz N.K., Sanguinetti M.C. Rate-dependent prolongation of cardiac action potentials by a methanesulfonanilide class III antiarrhythmic agent. Specific block of rapidly activating delayed rectifier K+ current by dofetilide. Circ Res. 1993; 71, 75-83.

[95] Vos M. A. Preclinical evaluation of antiarrhythmic drugs: new drugs should be safe to be successful. J Cardiovas Electrophysiol. 2001; 12, 1034-1036.

[96] MacKenzie I. Safety pharmacology requirements for the development of human cardiac/cardiovascular pharmaceuticals. Drug Dev Res. 2002; 55, 73-78.

[97] Koufaki M., Calogeropoulou T., Rekka E., Chryselis M., Papazafiri P., Gaitanaki C., Makriyannis A. Bifunctional agents for reperfusion arrhythmias: novel hybrid vitamin E/class I antiarrhythmics. Bioorg Med Chem. 2003; 11, 5209-5219.

[98] Chaitman, B.R., Skettino, S.L., Parker, J.O., Hanley, P., Meluzin, J., Kuch, J., Pepine, C.J., Wang, W., Nelson, J.J., Hebert, D.A., Wolff, A.A., 2004b. Anti-ischemic effects and long-term survival during ranolazine monotherapy in patients with chronic severe angina. $\mathrm{J}$ Am Coll Cardiol. 43, 1375-1382.

[99] Tomaselli G.F., Marban E. Electrophysiological remodeling in hypertrophy and heart failure. Cardiovasc Res. 1999; 42, 270-283.

[100] Wang Z., Tristani-Firouzi M., Xu Q., Lin M., Keating M.T., Sanguinetti M.C. Functional effects of mutations in KvLQT1 that cause long QT syndrome. J Cardiovasc Electrophysiol. 1999; 10, 817-826.

[101] Thollon C., Cambarrat C., Vian J., Prost J.F., Peglion J.L., Vilaine J.P. Electrophysiological effects of S 16257, a novel sino-atrial nodemodulator, on rabbit and guineapig cardiac preparations: comparison with UL-FS 49. Br J Pharmacol. 1994; 112, $37-42$.

[102] Bois P., Bescond J., Renaudon B., Lenfant J. Mode of action of bradycardic agent, S 16257, on ionic currents of rabbit sinoatrial node cells. Br J Pharmacol. 1996; 118, 1051-1057.

[103] Saint D.A. The cardiac persistent sodium current: an appealing therapeutic target? Br J Pharmacol. 2008; 153, 1133-1142.

[104] Balati B., Varro A., Papp J.G. Comparison of the cellular electrophysiological characteristics of canine left ventricular epicardium, M cells, endocardium and Purkinje fibres. Acta Physiol Scand. 1998; 164, 181-190.

[105] Shryock J.C., Belardinelli L. Inhibition of late sodium current to reduce electrical and mechanical dysfunction of ischaemic myocardium. Br J Pharmacol. 2008; 153, 11281132.

[106] Burashnikov A., Antzelevitch C. Atrial-selective sodium channel blockers: do they exist? J Cardiovasc Pharmacol. 2008; 52, 121-128.

[107] Wu L., Rajamani S., Li H., January C.T., Shryock J.C., Belardinelli L. Reduction of repolarization reserve unmasks the proarrhythmic role of endogenous late $\mathrm{Na}(+)$ current in the heart. Am J Physiol Heart Circ Physiol. 2009; 297, H1048-1057.

[108] Abdallah H., Jerling M. Effect of hepatic impairment on the multiple-dose pharmacokinetics of ranolazine sustained-release tablets. J Clin Pharmacol. 2005; 45, 802809.

[109] Joannides R., Moore N., Iacob M., Compagnon P., Lerebours G., Menard J.F., Thuillez C. Comparative effects of ivabradine, a selective heart rate-lowering agent, and propranolol on systemic and cardiac haemodynamics at rest and during exercise. Br J Clin Pharmacol. 2005; 61, 127-137. 
[110] Yaniv Y., Maltsev V.A., Ziman B.D., Spurgeon H.A., Lakatta E.G. The "funny" current (I(f)) inhibition by ivabradine at membrane potentials encompassing spontaneous depolarization in pacemaker cells. Molecules. 2012; 17(7), 8241-54.

[111] Camm A.J., Savelieva I. If inhibition with ivabradine: electrophysiological effects and safety. Drug Saf. 2008; 31, 95-107.

[112] Tardif J.C., Borer J.S. Efficacy of ivabradine, a selective I(f) inhibitor, in patients with chronic stable angina pectoris and diabetes mellitus. Am J Cardiol. 2010; 105, 29-35.

[113] Brendorp B., Pedersen O., Torp-Pedersen C., Sahebzadah N., Kober L. A benefitrisk assessment of class III antiarrhythmic agents. Drug Saf. 2002; 25, 847-865.

[114] Purerfellner H. Recent developments in cardiovascular drug therapy: treatment of atrial arrhythmias with new class III drugs and beyond. Curr Med Chem-Cardiovasc Hematol Agents. 2004; 2, 79-91.

[115] Tavazzi L., Mugelli A. Can If inhibition help in congestive heart failure? Dialogues in Cardiovascular Medicine. 2006; 11, 30-35. 


\section{ACKNOWLEDGEMENT}

I am especially thankful to my supervisors László Virág PhD for introducing me to cardiac cellular electrophysiology, and for providing me the opportunity for research in the laboratory, and to Professor András Varró MD, DSc for his continuous support and personal guidance at the Department of Pharmacology \& Pharmacotherapy. Their personal guidance and the helpful discussions were exceptionally useful during my work and allowed me to learn the critical thinking in the scientific field.

I am very grateful to Professor Julius Gy. Papp MD, DSc, academician and to István Koncz MD for their continuous support, criticism and suggestions.

I wish to thank my colleagues, Norbert Jost PhD; István Baczkó MD, PhD; Zoltán Husti MD for their continuous support and help in my work.

I am also very thankful to Zsuzsanna Molnár, Gyula Horváth, and Gábor Girst for their helpful technical assistance.

Finally, I wish to thank, and dedicate this thesis to my whole family and to my friends for their love, help and encouragement.

The publication is supported by the European Union and co-funded by the European Social Fund. Project title: "Broadening the knowledge base and supporting the long term professional sustainability of the Research University Centre of Excellence at the University of Szeged by ensuring the rising generation of excellent scientists." Project number: TÁMOP-4.2.2/B-10/1-2010-0012. 